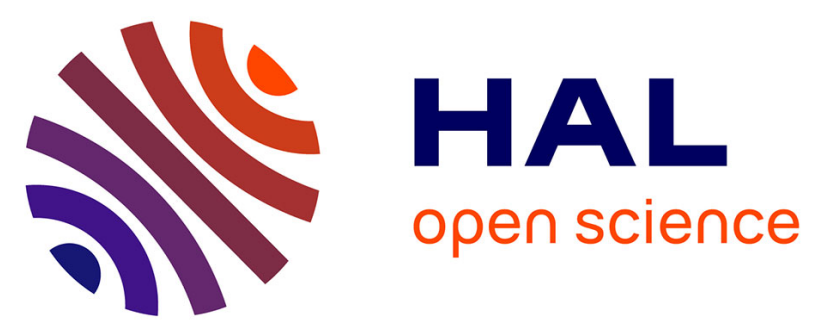

\title{
Review on the catalytic tri-reforming of methane - Part I: Impact of operating conditions, catalyst deactivation and regeneration
}

Doan Pham Minh, Xuan-Huynh Pham, Tan Ji Siang, Dai-Viet N.Vo

\section{- To cite this version:}

Doan Pham Minh, Xuan-Huynh Pham, Tan Ji Siang, Dai-Viet N.Vo. Review on the catalytic trireforming of methane - Part I: Impact of operating conditions, catalyst deactivation and regeneration. Applied Catalysis A: General, 2021, 621, pp.1-18/118202. 10.1016/j.apcata.2021.118202 . hal-03224215

\section{HAL Id: hal-03224215 \\ https://imt-mines-albi.hal.science/hal-03224215}

Submitted on 21 May 2021

HAL is a multi-disciplinary open access archive for the deposit and dissemination of scientific research documents, whether they are published or not. The documents may come from teaching and research institutions in France or abroad, or from public or private research centers.
L'archive ouverte pluridisciplinaire $\mathbf{H A L}$, est destinée au dépôt et à la diffusion de documents scientifiques de niveau recherche, publiés ou non, émanant des établissements d'enseignement et de recherche français ou étrangers, des laboratoires publics ou privés. 


\title{
Review on the catalytic tri-reforming of methane - Part I: Impact of operating conditions, catalyst deactivation and regeneration
}

\author{
Doan Pham Minh $^{\mathrm{a}, \mathrm{b}, *}$, Xuan-Huynh Pham ${ }^{\mathrm{b}}$, Tan Ji Siang ${ }^{\mathrm{c}}$, Dai-Viet N. Vo ${ }^{\mathrm{d}}$ \\ ${ }^{a}$ Institute of Research and Development, Duy Tan University, Da Nang 550000, Vietnam \\ ${ }^{\mathrm{b}}$ Université de Toulouse, IMT Mines Albi, UMR CNRS 5302, Centre RAPSODEE, Campus Jarlard, F-81013 Albi Cedex 09, France \\ ${ }^{\mathrm{c}}$ School of Chemical and Energy Engineering, Faculty of Engineering, Universiti Teknologi Malaysia, 81310 UTM Johor Bahru, Johor, Malaysia \\ ${ }^{\mathrm{d}}$ Center of Excellence for Green Energy and Environmental Nanomaterials (CE@GrEEN), Nguyen Tat Thanh University, 300A Nguyen Tat Thanh, District 4, Ho Chi \\ Minh City 755414, Vietnam
}

Keywords:

Syngas

Tri-reforming of methane

Heterogeneous catalysis

Operational conditions

Catalyst deactivation

Catalyst regeneration

\begin{abstract}
A B S T R A C T
Tri-reforming of methane (TRM) allows the production of syngas with a low environmental impact, an optimal energetic consumption, and a modular $\mathrm{H}_{2} / \mathrm{CO}$ molar ratio. However, despite a large number of publications devoted to TRM reaction, this process is still in its infancy and faces technical issues due to the catalyst deactivation by the formation of solid carbon, thermal sintering, vapor-solid reactions, and poisoning. Moreover, TRM reaction is also highly dependent on the operational conditions. This article provides a critical analysis of the last achievements on the TRM reaction. First, the thermodynamic, kinetic and mechanism aspects are presented and commented. Then, the impact of the operational conditions is analyzed. Finally, the main reasons of catalyst deactivation and the associated methods for catalyst regeneration are discussed. In parallel, catalytic efficiency is tentatively linked to physico-chemical properties of the catalyst, and recommendations are proposed for the future work on TRM process.
\end{abstract}

\section{Introduction}

Tri-reforming of methane (TRM) refers to the reaction of methane with a mixture of water, carbon dioxide and oxygen to produce syngas. Thus, TRM simultaneously combines three reactions of steam reforming of methane (SRM), dry reforming of methane (DRM) and partial oxidation of methane (POM) in which methane is reformed with the respective water, carbon dioxide and oxygen [1]. TRM is particularly interesting for the valorization of biogas - a promising renewable resource of which the global production continuously increases [2-4], flue gas which simultaneously contains water, carbon dioxide and oxygen and heat energy [5-7], as well as carbon dioxide recovered from CCU (carbon capture and utilization) processes [8]. Thus, TRM can play an important role in the development of renewable energy carriers such as syngas, accompanied by $\mathrm{CO}_{2}$ emissions reduction - a main greenhouse gas.

Compared to individual SRM, DRM and POM, TRM allows controlling the molar ratio of $\mathrm{H}_{2} / \mathrm{CO}$ by varying feed composition. This is of particular interest because various molar ratios of $\mathrm{H}_{2} / \mathrm{CO}$ are required for different downstream processes such as methanol synthesis, Fisher-
Tropsch synthesis, hydrogen production via water-gas-shift, methanation, etc. [5,9-11]. As discussed in the next section, TRM is generally carried out at high temperature (ca. $700-900{ }^{\circ} \mathrm{C}$ ) and atmospheric pressure, because of the stability of the reactants [12]. Particularly, TRM process needs a solid catalyst to drive the kinetic and the selectivity of the reaction [13]. However, catalyst deactivation remains as a major challenge in methane reforming, by various reasons such as thermal sintering, re-oxidation of metallic active phase, coke deposition, etc. [3, 14,15].

During the last two decades, works devoted to TRM exponentially increased. More than 120 papers have been identified by Web of Science with "tri-reforming" and "methane" as keywords. The present work firstly reminds the fundamental aspects of TRM reaction including the thermodynamics and reaction mechanisms. Then, the impact of operating conditions is discussed. Finally, a critical analysis on the catalyst deactivation and tentative regeneration solutions is addressed. For each part, discussions with recommendations are provided.

\footnotetext{
* Corresponding author.

E-mail addresses: phamminhdoan@duytan.edu.vn, doan.phamminh@mines-albi.fr (D. Pham Minh).
} 

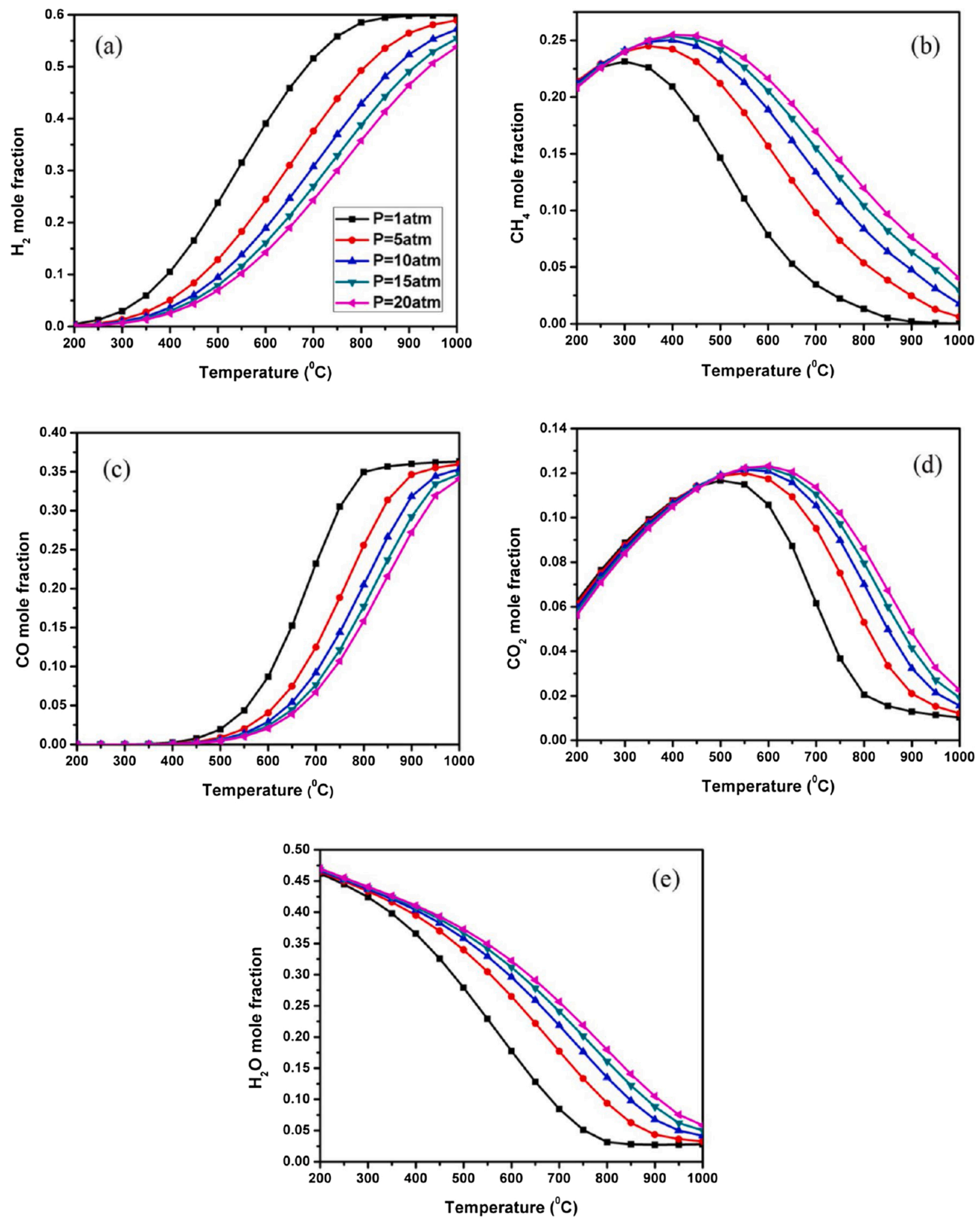

Fig. 1. Effect of the temperature and pressure on the equilibrium in TRM: (a) $\mathrm{H}_{2}$, (b) $\mathrm{CH}_{4}$, (c) $\mathrm{CO}$, (d) $\mathrm{CO}_{2}$, and (e) $\mathrm{H}_{2} \mathrm{O}$ mole fractions. Feed composition: $\mathrm{CH}_{4} / \mathrm{CO}_{2}$ / $\mathrm{H}_{2} \mathrm{O} / \mathrm{O}_{2}=1 / 0.475 / 0.475 / 0.1$. Reprinted with permission from [16]. Copyright (2014) American Chemical Society. 


\section{Basics of TRM reaction}

\subsection{Thermodynamics}

A detailed study on the thermodynamic aspects of TRM was done by Zhang et al. [16]. Fig. 1 shows the effect of the temperature and pressure. High temperatures $\left(\geq 800{ }^{\circ} \mathrm{C}\right)$ are indispensable to obtain high reactant conversions. On the other hand, the increase of the pressure disfavors TRM reaction. However, reforming reactors typically operate at high pressures (3-20 bar) to decrease reactor size and to meet the high pressure needs of downstream applications of syngas [17]. $\mathrm{H}_{2}$ and $\mathrm{CO}$ are formed as the two main products and their formation is strongly favored at high temperature. Solid carbon as a by-product is omnipresent within the temperature range studied $\left(100-1000{ }^{\circ} \mathrm{C}\right)$, but is strongly limited above $850{ }^{\circ} \mathrm{C}$ (at 1 bar) [18]. Similar results were obtained by Phan [19], and Borreguero et al. [20].

The increase of $\mathrm{CO}_{2}$ or $\mathrm{H}_{2} \mathrm{O}$ contents in the feed composition is favorable for methane conversion, and limits solid carbon formation [16-19]. For example, by keeping unchanged the initial amounts of $\mathrm{CH}_{4}$, $\mathrm{CO}_{2}$ and $\mathrm{O}_{2}$ at 2.0, 1.0 and $0.1 \mathrm{~mol}$, respectively, the increase of the initial amount of $\mathrm{H}_{2} \mathrm{O}$ from 0.8 to $1.0 \mathrm{~mol}$ allows lowering the temperature for complete $\mathrm{CH}_{4}$ conversion from 1000 to $900{ }^{\circ} \mathrm{C}$, and the temperature for the nearly-complete suppression of solid carbon from 1000 to less than $850{ }^{\circ} \mathrm{C}$. In parallel, the molar ratio of $\mathrm{H}_{2} / \mathrm{CO}$ increases from ca. 1.6-1.65 [18].

The increase of $\mathrm{O}_{2}$ content in the feed composition highly favors methane conversion [16]. However, this also strongly decreases $\mathrm{CO}_{2}$ conversion because of the competition between $\mathrm{O}_{2}$ and $\mathrm{CO}_{2}$ for reforming $\mathrm{CH}_{4}$ [16]. In some cases, $\mathrm{CO}_{2}$ conversion could be even negative due to its formation by $\mathrm{CH}_{4}$ combustion [16].

\subsection{Kinetic and mechanism aspects}

To date, only few works are devoted to kinetic and mechanistic investigation in TRM due to its complexity involving multiple main reforming reactions. Song and Pan [6] studied TRM over nickel-based catalysts prepared on various supports $\left(\mathrm{Ni} / \mathrm{MgO}, \mathrm{Ni} / \mathrm{Al}_{2} \mathrm{O}_{3}\right.$ and $\mathrm{Ni} / \mathrm{M}$ $\mathrm{gO} / \mathrm{CeZrO}$ ), and proposed kinetic models based on power law and validated them by experimental data. They mostly kept unchanged the partial pressure of $\mathrm{CH}_{4}$ and $\mathrm{O}_{2}$ in order to only study the impact of $\mathrm{H}_{2} \mathrm{O}$ and $\mathrm{CO}_{2}$ reactants. Thus, the general kinetic equation is given below:

$r_{i}=\operatorname{Aexp}\left(\frac{-E_{a p p, i}}{R T}\right)\left(P_{\mathrm{CO}_{2}}\right)^{\alpha, i}\left(P_{\mathrm{H}_{2} \mathrm{O}}\right)^{\beta, i}$

where $i: \mathrm{CH}_{4}$ or $\mathrm{CO}_{2} ; r_{i}$ : reaction rate; $\alpha$ and $\beta$ : partial order; $E_{a p p}$ : apparent activation energy; and A: pre-exponential factor.

From experimental data, the authors could calculate the conversions of $\mathrm{CH}_{4}$ and $\mathrm{CO}_{2}$ as functions of the reaction temperature, and partial pressures of $\mathrm{CO}_{2}$ and $\mathrm{H}_{2} \mathrm{O}$. Then, from the Eq. 1, they could plot $\ln (r$ $\left.\left(\mathrm{CH}_{4}\right)\right)$ or $\ln (r(\mathrm{CO} 2))$ versus $\ln \left(\mathrm{P}_{\mathrm{CO} 2}\right)$ or $\ln \left(\mathrm{P}_{\mathrm{H} 2 \mathrm{O}}\right)$, and $\left.\ln \left({ }_{(\mathrm{CH} 4}\right)\right)$ or $\ln (r$ $(\mathrm{CO} 2)$ ) versus $1 / T$ in order to determine the activation energy and the partial reaction order $\alpha$ and $\beta$. The results obtained showed that the variation of the $\mathrm{CO}_{2}$ partial pressure impacted $\mathrm{CH}_{4}$ conversion. Depending on support nature, this impact is favorable over $\mathrm{Ni} / \mathrm{Al}_{2} \mathrm{O}_{3}$ and unfavorable over $\mathrm{Ni} / \mathrm{MgO}$ [6]. It was tentatively explained by the interaction of $\mathrm{CO}_{2}$ with catalyst surface according to the Langmuir-Hinshelwood mechanism. Both $\mathrm{CH}_{4}$ and $\mathrm{CO}_{2}$ adsorb on catalyst surface via single- or dual-site mechanisms, followed by surface reaction forming products. $\mathrm{CH}_{4}$ dissociation was reportedly activated on Ni sites [21] while the support surface was responsible for $\mathrm{CO}_{2}$ activation [6]. In this context, Ni-support interface is of crucial importance for reforming reaction where both surface-active intermediates from adsorbed $\mathrm{CH}_{4}$ and $\mathrm{CO}_{2}$ species are readily presented $[6,22,23]$. Undeniably, the extent of $\mathrm{CO}_{2}$ activation is highly dependent on the $\mathrm{CO}_{2}$ interaction associated with support nature. However, a stronger $\mathrm{CO}_{2}$-catalyst interaction (in the case of $\mathrm{Ni} / \mathrm{MgO}$ ) could suppress the formation of active surface for $\mathrm{CH}_{4}$ adsorption, which led to a decline in $\mathrm{CH}_{4}$ conversion rate and as a result, a negative reaction order of $P_{\mathrm{CO}_{2}}$. On the other hand, weak $\mathrm{H}_{2} \mathrm{O}$-catalyst interaction (in the case of $\mathrm{Ni} / \mathrm{Al}_{2} \mathrm{O}_{3}$ ) led to a positive reaction order with respect to $P_{\mathrm{CO}_{2}}$ [6]. The increase of $\mathrm{H}_{2} \mathrm{O}$ partial pressure caused a decrease in $\mathrm{CO}_{2}$ conversion, leading to a negative reaction order for $\mathrm{CO}_{2}$ conversion with respect to $P_{\mathrm{H}_{2} \mathrm{O}}$ [6]. This matches well with thermodynamic prediction and confirms the competition of these two oxidants to reform $\mathrm{CH}_{4}$ [19].

Maciel et al. [13] performed TRM over $\mathrm{Ni} / \alpha-\mathrm{Al}_{2} \mathrm{O}_{3}$ in a fixed-bed reactor to experimentally validate their four-step TRM mechanism. The first step consists of three individual SRM, DRM and POM reactions to produce syngas, and complete methane oxidation which are considered as heterogeneous catalytic reactions. These individual reactions were described by a global observed equation as shown in the 3rd column of the Table 1 . The second step is the methane cracking. The third and the fourth steps correspond to the Boudouard reaction and reverse water-gas-shift reaction (RWGS), respectively [13]. In this context, kinetic rate expressions were proposed for each step (Table 1) on the basis of the Langmuir-Hinshelwood mechanism, which in turn allowed the deriving $\mathrm{CH}_{4}$ and $\mathrm{CO}_{2}$ consumption rates, and $\mathrm{H}_{2}$ and $\mathrm{CO}$ formation rates (Table 1). By plotting experimental data of $\mathrm{CH}_{4}, \mathrm{CO}_{2}, \mathrm{H}_{2}$ and $\mathrm{CO}$ concentration $\left(\mathrm{mol} \mathrm{m}^{-3}\right)$ as a function of space time $\left(\mathrm{kg} \mathrm{s} \mathrm{m}^{-3}\right)$ and comparing with the model, the proposed mechanism was successfully validated, as shown in [13] (Fig. 2).

As previously stated, TRM combines three individual reactions of SRM, DRM and POM. Low oxygen content $(<5$ vol.\%) in the initial mixture is usually applied in view of landfill gas and flue gas valorization [4-7]. Outlet oxygen concentration in TRM is usually undetectable [19, 24]. Thus, kinetic and mechanistic studies could be based on those for SRM and DRM, as suggested by Garcia-Vargas et al. [24]. Three individual reactions of SRM, DRM and WGS and associated kinetic models available in the literature were considered as shown in Table $2[25,26]$. By comparing experimental data with theoretical models using nonlinear regression procedure, the rate constant of each individual

Table 1

Four-step TRM mechanism and associated kinetic equations.

\begin{tabular}{|c|c|c|c|}
\hline Step & Reaction steps & $\begin{array}{l}\text { Observed reaction } \\
\text { steps }\end{array}$ & Kinetic model \\
\hline I & $\begin{array}{l}\text { a. } \mathrm{CH}_{4}(\mathrm{~g})+ \\
\mathrm{CO}_{2}(\mathrm{~g}) \Leftrightarrow 2 \mathrm{CO} \\
(\mathrm{g})+2 \mathrm{H}_{2}(\mathrm{~g}) \\
\text { b. } \mathrm{CH}_{4}(\mathrm{~g})+ \\
\mathrm{H}_{2} \mathrm{O}(\mathrm{g}) \Leftrightarrow \mathrm{CO} \\
(\mathrm{g})+3 \mathrm{H}_{2}(\mathrm{~g}) \\
\text { c. } \mathrm{CH}_{4}(\mathrm{~g})+ \\
\mathrm{O}_{2}(\mathrm{~g}) \Leftrightarrow \mathrm{CO}(\mathrm{g}) \\
+2 \mathrm{H}_{2}(\mathrm{~g}) \\
\text { d. } \mathrm{CH}_{4}(\mathrm{~g})+ \\
2 \mathrm{O}_{2}(\mathrm{~g}) \Leftrightarrow \\
\mathrm{CO}_{2}(\mathrm{~g})+2 \mathrm{H}_{2} \mathrm{O} \\
(\mathrm{g})\end{array}$ & $\begin{array}{l}\mathrm{CH}_{4}(\mathrm{~g})+5 / 8 \mathrm{O}_{2}(\mathrm{~g}) \Leftrightarrow \\
\mathrm{CO}(\mathrm{g})+7 / 4 \mathrm{H}_{2}(\mathrm{~g})+1 / \\
4 \mathrm{H}_{2} \mathrm{O}(\mathrm{g})\end{array}$ & $\begin{array}{l}r_{I}= \\
k_{1} \frac{K_{\mathrm{CH}_{4}} C_{\mathrm{CH}_{4}} \cdot K_{\mathrm{O}_{2}} C_{\mathrm{O}_{2}}}{\left(1+K_{\mathrm{CH}_{4}} C_{\mathrm{CH}_{4}} \cdot K_{\mathrm{O}_{2}} C_{\mathrm{O}_{2}}\right)^{2}}\end{array}$ \\
\hline II & $\begin{array}{l}\text { e. } \mathrm{CH}_{4}(\mathrm{~g})+\mathrm{C} \\
(\mathrm{s}) \Leftrightarrow 2 \mathrm{H}_{2}(\mathrm{~g})\end{array}$ & $\begin{array}{l}\mathrm{CH}_{4}(\mathrm{~g}) \Leftrightarrow \mathrm{C}(\mathrm{s})+ \\
2 \mathrm{H}_{2}(\mathrm{~g})\end{array}$ & $r_{I I}=k_{2} \frac{K_{C_{4}} C_{C H_{4}}}{1+K_{C_{4}} C_{C_{4}}}$ \\
\hline III & $\begin{array}{l}\text { f. } 2 \mathrm{CO}(\mathrm{g}) \Leftrightarrow \mathrm{C} \\
(\mathrm{s})+\mathrm{CO}_{2}(\mathrm{~g})\end{array}$ & $\begin{array}{l}2 \mathrm{CO}(\mathrm{g}) \Leftrightarrow \mathrm{C}(\mathrm{s})+ \\
\mathrm{CO}_{2}(\mathrm{~g})\end{array}$ & $r_{I I I}=k_{3} C_{C O}^{2}$ \\
\hline \multirow[t]{6}{*}{ IV } & $\begin{array}{l}\text { g. } \mathrm{CO}_{2}(\mathrm{~g})+ \\
\mathrm{H}_{2}(\mathrm{~g}) \Leftrightarrow \mathrm{CO}(\mathrm{g}) \\
+\mathrm{H}_{2} \mathrm{O}(\mathrm{g})\end{array}$ & $\begin{array}{l}\mathrm{CO}_{2}(\mathrm{~g})+\mathrm{H}_{2}(\mathrm{~g}) \Leftrightarrow \mathrm{CO} \\
(\mathrm{g})+\mathrm{H}_{2} \mathrm{O}(\mathrm{g})\end{array}$ & $r_{4}=k_{4}\left(C_{\mathrm{H}_{2}} C_{\mathrm{CO}_{2}}-\frac{C_{\mathrm{CO}} C_{\mathrm{H}_{2} \mathrm{O}}}{K_{e q}}\right)$ \\
\hline & & $\begin{array}{l}\text { Parameters } \\
\text { (consumption or } \\
\text { formation rate) }\end{array}$ & $\begin{array}{l}\text { Consumption or formation } \\
\text { rate equation }\end{array}$ \\
\hline & & $\mathrm{CH}_{4}$ consumption rate & $R_{C H_{4}}=-r_{I}-r_{I I}$ \\
\hline & & $\mathrm{CO}_{2}$ consumption rate & $R_{C_{2}}=r_{I I I}-r_{I V}$ \\
\hline & & $\mathrm{H}_{2}$ formation rate & $R_{H_{2}}=\frac{7}{4} r_{I}+2 r_{I I}-r_{I V}$ \\
\hline & & $\mathrm{CO}$ formation rate & $R_{C O}=r_{I}-2 r_{I I I}+r_{I V}$ \\
\hline
\end{tabular}

Adapted with permission from [13]. Copyright (2010) Springer Nature. 

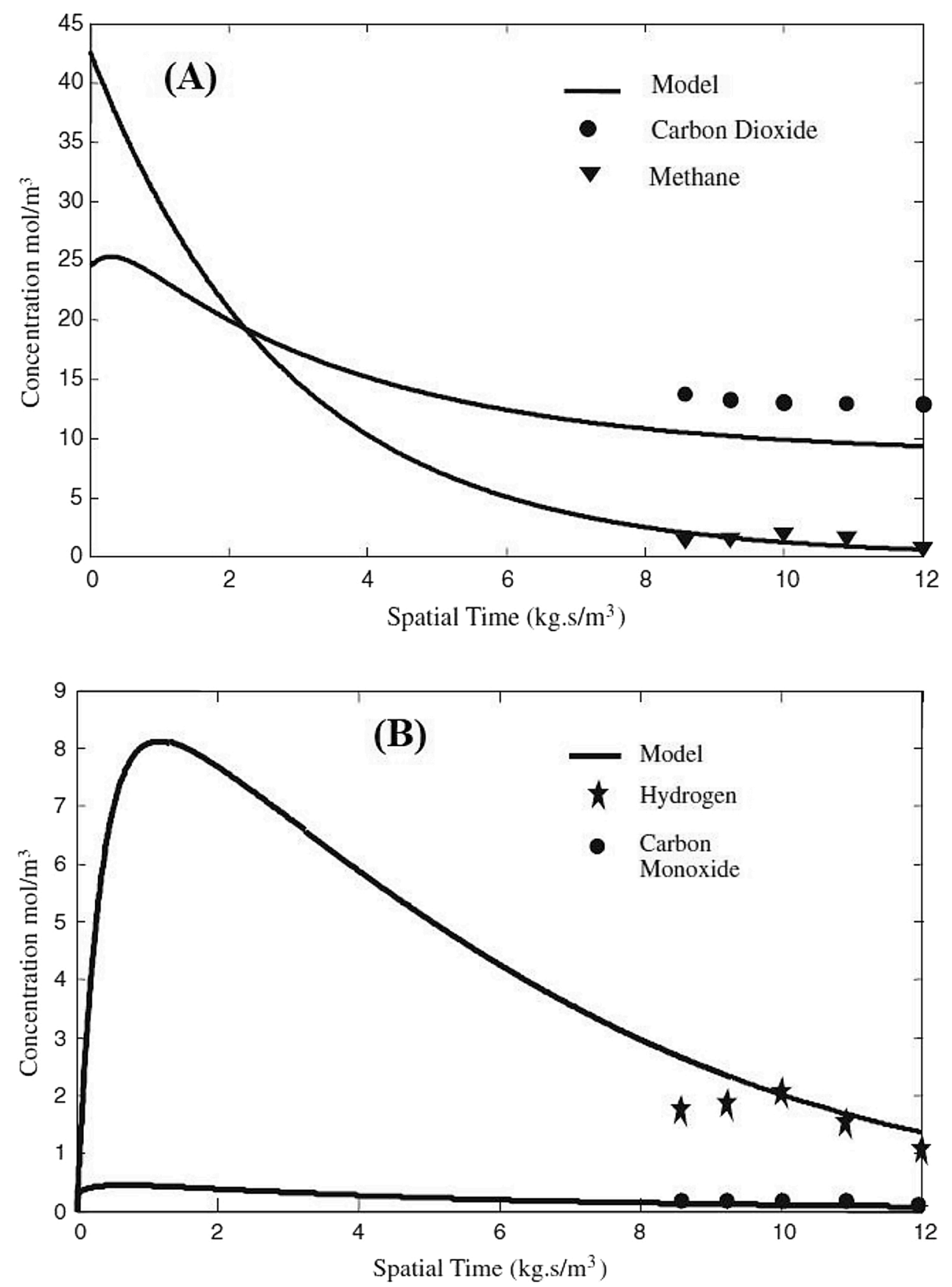

Fig. 2. Model predictions for concentration profiles of: (A) the reactants, and (B) the products in the tri-reforming process. Reaction conditions: $850{ }^{\circ} \mathrm{C}$, 1 bar, $5.75 \mathrm{wt} \% \mathrm{Ni} / \mathrm{c}-\mathrm{Al}_{2} \mathrm{O}_{3} ;$ Molar ratio of $\mathrm{CH}_{4}: \mathrm{CO}_{2}: \mathrm{H}_{2} \mathrm{O}: \mathrm{O}_{2}=1: 0.49: 0.3: 0.04$. Adapted with permission from [13]. Copyright (2010) Springer Nature.

reaction could be obtained within the temperature range studied, and the proposed models could be validated with a relatively-acceptable average error. Then, the pre-exponential factor $(A)$ and the activation energy $\left(E_{a}\right)$ of these reactions were determined (Table 2), which matched with the values previously reported [24]. It is worth noting that these models did not consider the formation of by-products such as solid carbon.

Cho et al. [1] proposed and validated the kinetic model of TRM reaction with a "burner tester" - a 2.5 L TRM reactor integrated in the global process of dimethyl ether production from natural gas. The burner tester was fed with preheated natural gas, $\mathrm{CO}_{2}$, steam and $\mathrm{O}_{2}$. Natural gas is partially burned in the homogeneous zone. Then, the mixture entered into the heterogeneous catalytic zone where $\mathrm{NiO}-\mathrm{Mg} / \mathrm{Ce}-\mathrm{ZrO}_{2} / \mathrm{Al}_{2} \mathrm{O}_{3}$ catalyst was used. The authors also used global catalytic surface reactions with the associated kinetic models available in the literature, as well as JACOBIAN ${ }^{\circledR}$ dynamic modeling and optimization software to describe the kinetics of the heterogamous zone. Experimental data were well described by the model, even at high $\mathrm{CH}_{4}$ conversion (90-98 \%) [1] (Fig. 3).

All the kinetic models presented above did not allow understanding elemental steps of the TRM reaction. Specific characterizations of surface and interface physico-chemistry involved in TRM reaction should be conducted to determine reaction intermediates, and thus get access to the details of TRM reaction mechanism. DFT calculations and microkinetic simulations could be also performed as previously applied in other processes such as DRM [27], and SRM [28,29]. 
Table 2

Chemical reaction and kinetic models considered in TRM by Garcia-Vargas et al. [24]; $k$ : rate constant; $K$ : equilibrium constant, and $P$ : partial pressure.

\begin{tabular}{|c|c|c|c|}
\hline $\begin{array}{l}\text { Chemical } \\
\text { reaction }\end{array}$ & Kinetic model & $\begin{array}{l}\text { Pre- } \\
\text { exponential } \\
\text { factor, A (mol } \\
\mathrm{s}^{-1} \mathrm{kPa}^{-1} \text { ) }\end{array}$ & $\begin{array}{l}\text { Activation } \\
\text { energy, } E_{a} \\
\left(\mathrm{~kJ} \mathrm{~mol}^{-1}\right)\end{array}$ \\
\hline SRM: & $r_{S R M}=k_{1} \cdot P_{C_{4}}$ & & \\
\hline $\begin{array}{l}\mathrm{CH}_{4}(\mathrm{~g})+ \\
\quad \mathrm{H}_{2} \mathrm{O}(\mathrm{g}) \\
\Leftrightarrow \mathrm{CO}(\mathrm{g}) \\
+3 \mathrm{H}_{2}(\mathrm{~g})\end{array}$ & $\begin{array}{l}\left(\frac{P_{C O} \cdot P_{H_{2}}^{3}}{P_{C H_{4}} \cdot P_{H_{2} O} \cdot K_{S R M}}\right) \\
\text { with } K_{S R M}=1.198 \cdot 10^{17} \\
e^{(-26830 / T)}\end{array}$ & 85.77 & 74.72 \\
\hline $\begin{array}{l}\text { DRM: } \\
\qquad \mathrm{CH}_{4}(\mathrm{~g})+ \\
\mathrm{CO}_{2}(\mathrm{~g}) \Leftrightarrow \\
2 \mathrm{CO}(\mathrm{g})+ \\
2 \mathrm{H}_{2}(\mathrm{~g})\end{array}$ & $\begin{array}{l}r_{D R M}=k_{2} \cdot P_{C H_{4}} \cdot(1- \\
\left.\frac{P_{C O}^{2} \cdot P_{H_{2}}^{2}}{P_{C H_{4}} \cdot P_{H_{2} O} \cdot K_{D R M}}\right) \\
\text { with } K_{D R M}=6.780 \cdot 10^{18} \\
e^{(-31230 / T)}\end{array}$ & 70.99 & 77.82 \\
\hline $\begin{array}{l}\text { WGS: } \\
\qquad \mathrm{CO}(\mathrm{g})+ \\
\mathrm{H}_{2} \mathrm{O}(\mathrm{g}) \\
\Leftrightarrow \mathrm{CO}_{2}(\mathrm{~g}) \\
+\mathrm{H}_{2}(\mathrm{~g})\end{array}$ & $\begin{array}{l}r_{W G S}=k_{3} \cdot\left(\frac{P_{C O} \cdot P_{\mathrm{H}_{2} \mathrm{O}}}{P_{\mathrm{H}_{2}}}-\frac{P_{\mathrm{CO}_{2}}}{K_{W G S}}\right) \\
\text { with } K_{W G S}=10\left(\frac{2078}{T}-2.029\right)\end{array}$ & 149.92 & 54.26 \\
\hline
\end{tabular}

\section{Impacts of operating conditions}

As previously highlighted in the thermodynamic section, TRM is highly sensitive to reaction conditions such as the temperature, pressure, gas hourly space velocity (GHSV), and feed composition. These parameters not only affect the thermodynamic equilibrium and the kinetic of the involved reactions in TRM, but also the stabilization of the catalyst studied. Known as a synergetic combination of individual processes of SRM, DRM and POM, and with the implication of many other equilibria such as water-gas-shift reaction (WGS), reverse water-gas-shift reaction (RWGS), methane cracking etc.), TRM involves in a series of complex endothermic (SRM, DRM, RWGS etc.) and exothermic (POM, WGS etc.) reactions. Thus, it is possible to perform TRM process at lower energy demand compared to the SRM and DRM, or even under autothermal mode by modifying feeding composition. In addition, the simultaneous occurrence of different equilibria in TRM process, a conventional catalyst devoted to the individual SRM, DRM or POM cannot be systematically applied to TRM [30]. A comprehensive study on the relationship between the operating conditions of TRM and the catalyst efficiency is needed, which is addressed within this section, allowing the

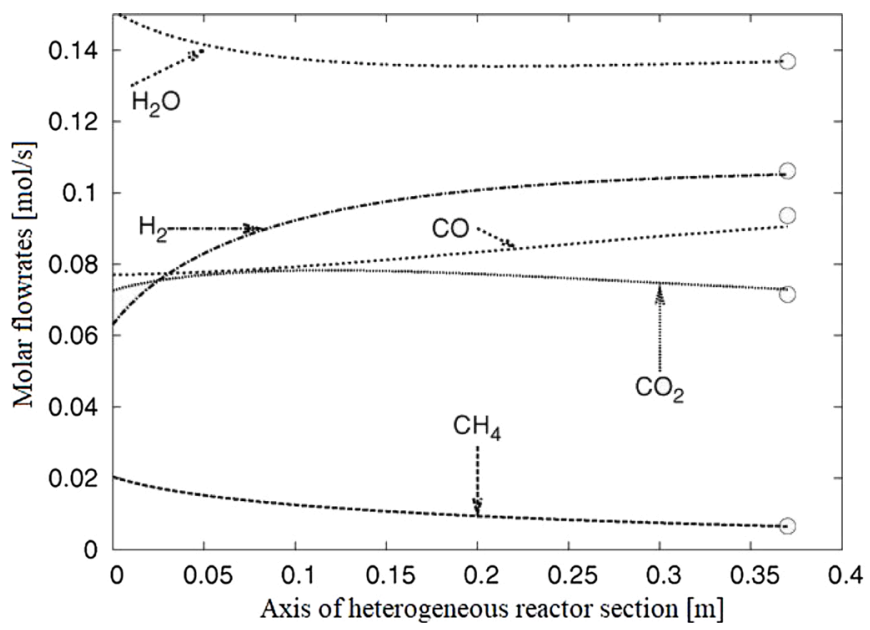

with the thermodynamic prediction presented above.

\subsection{Operating temperature}

The operating temperature is the most important parameter in TRM as it determines the thermodynamic and the kinetic of the reactions and also can impact catalyst properties such as the specific surface area, the metal dispersion, etc. In general, TRM requires high operating temperatures, above $700{ }^{\circ} \mathrm{C}$ (Fig. 1).

García-Vargas et al. [24] performed TRM over a Ni-Mg/ $\beta$-SiC catalyst within $407-737{ }^{\circ} \mathrm{C}$ (reaction conditions: different composition of inlet gas with a total flow of $100 \mathrm{~N} \mathrm{~mL} \min ^{-1}$ using $\mathrm{N}_{2}$ as balance, $\mathrm{GHSV}=60000 \mathrm{~N} \mathrm{~mL} \mathrm{~h}^{-1} \mathrm{~g}^{-1}$ ). At low operating temperatures, WGS reaction was predominant. Thus, instead of being consumed, $\mathrm{CO}_{2}$ could be formed, which lead to a negative conversion of this reactant. On the other hand, $\mathrm{H}_{2}$ production was favoured, which resulted to an increase of the molar ratio of $\mathrm{H}_{2} / \mathrm{CO}$. At high operating temperatures, the endothermic SRM and DRM reactions were favoured rather than WGS reaction. Consequently, high $\mathrm{CH}_{4}$ and $\mathrm{CO}_{2}$ conversions could be obtained [24]. Regarding the characteristics of the catalyst system, the reduction curve (TPR) started at around $387{ }^{\circ} \mathrm{C}$, reached peak at $737{ }^{\circ} \mathrm{C}$ and finished at around $920^{\circ} \mathrm{C}$. The quantitative TPR analysis showed that the reduction degree reached $63.7 \%$ at $920^{\circ} \mathrm{C}$, confirming that the reduction of $\mathrm{Ni}$ was not easy with this catalyst system. Unfortunately, the lack of information on the reduction temperature of the catalyst, and on the characterisations of the used catalyst did not allow a further assessment on the influence of the reaction temperature on the catalyst system, especially in term of reducibility, specific surface, and carbonaceous deposition.

Maciel et al. [13] investigated TRM over $\mathrm{Ni} / \mathrm{Al}_{2} \mathrm{O}_{3}$ catalyst within the temperature range of 650 and $950{ }^{\circ} \mathrm{C}$ (reaction conditions: $0.53 \mathrm{~g}$ of Cat. Ni (5.75 wt\%)/ $/ \mathrm{Al}_{2} \mathrm{O}_{3}, 1.0$ bar; $\mathrm{CH}_{4}: \mathrm{CO}_{2}: \mathrm{H}_{2} \mathrm{O}: \mathrm{O}_{2}=1: 0.49: 0.3: 0.04$ ). Prior to the test, the catalyst was reduced at $700{ }^{\circ} \mathrm{C}$ for $2 \mathrm{~h}$. Below $850{ }^{\circ} \mathrm{C}$, RWGS was predominant resulting in a low hydrogen yield (4.4 $\%)$. At higher temperatures $\left(>850{ }^{\circ} \mathrm{C}\right)$, hydrogen yield increased up to $37 \%$, together with high methane conversion ( $96 \%$ ) and carbon dioxide conversion (45\%). TPR analysis was not conducted, but it is possible that the in-situ reduction at $700{ }^{\circ} \mathrm{C}$ before TRM test was not enough to reduction totally $\mathrm{Ni}$ species into metallic $\mathrm{Ni}$, since $\mathrm{NiAl}_{2} \mathrm{O}_{4}$ was revealed by XRD. Thus, the high methane and carbon dioxide conversions above $850{ }^{\circ} \mathrm{C}$ could be due to the impact of the reaction temperature, but also the better Ni reduction during the TRM reaction its-self. This catalyst system possessed a high thermal stability within the temperature range investigated, explained by a relatively low carbon content $(0.3-0.36 \mathrm{wt}$

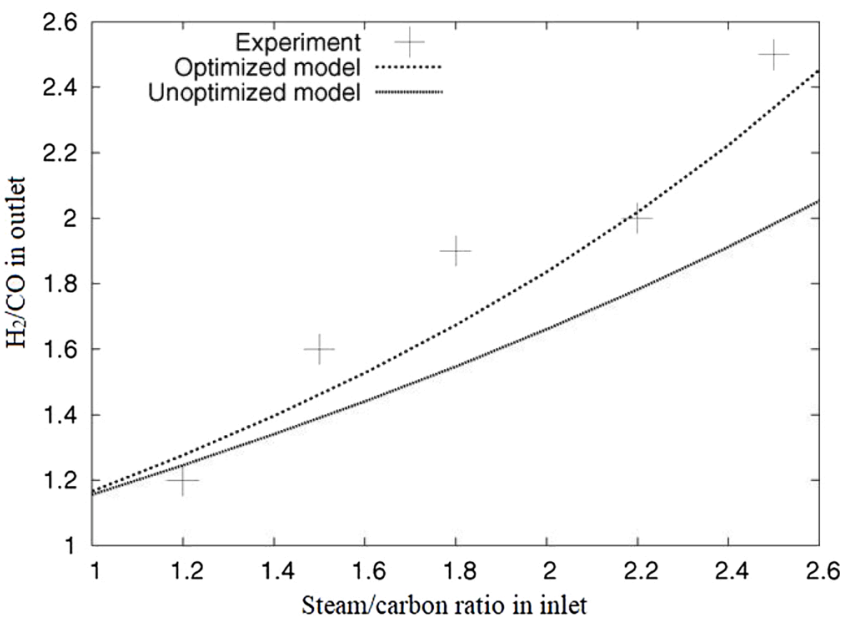

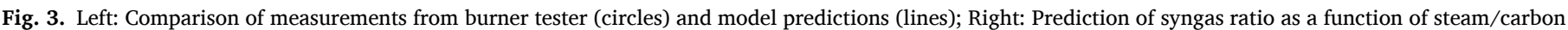
ratio in feed. Reproduced with permission from [1], Copyright 2009 Elsevier. 
$\%)$ in the used catalysts.

The performance of $\mathrm{Ni} / \mathrm{SiO}_{2}$ catalyst in TRM was investigated by Majewski and Wood [31]. Fig. 4 (A) evidenced the dependence of $\mathrm{CH}_{4}$ and $\mathrm{CO}_{2}$ conversions and $\mathrm{H}_{2} / \mathrm{CO}$ ratio on the reaction temperature at $550-750^{\circ} \mathrm{C}$. So, the catalyst was active at relatively moderate reaction temperature of $550{ }^{\circ} \mathrm{C}$. Unfortunately, only BET, XRD, FTIR and TGA-TPO were performed with the fresh and/or used catalysts, which were not enough to explain the catalytic activity observed at $550{ }^{\circ} \mathrm{C}$. Coke deposition was observed at $550^{\circ} \mathrm{C}$ but it was negligible at $750{ }^{\circ} \mathrm{C}$, as highlighted by SEM analysis of the used catalysts (Fig. 4 (B) and (C)). The authors also shown that the structure of the catalyst systems did not significantly change after TRM reaction, as evidenced by the presences of all the characteristic bands in FTIR. However, Ni sintering was identified in the used catalyst at $750{ }^{\circ} \mathrm{C}$ as the FTIR bands of nickel phyllosilicate $\left(3649,3629,711\right.$ and $670 \mathrm{~cm}^{-1}$ ) became less intensive compared to those of the fresh catalyst and the used catalyst at $550{ }^{\circ} \mathrm{C}$. The sintering would be better evidenced by techniques such as HRTEM.

Walker et al. [32] performed TRM reactions over Ni-MgO-(Ce, $\mathrm{Zr}) \mathrm{O}_{2}$ under controlled temperatures between 750 and $850{ }^{\circ} \mathrm{C}$. At $750{ }^{\circ} \mathrm{C}$, a low $\mathrm{CO}_{2}$ conversion and a high $\mathrm{H}_{2} / \mathrm{CO}$ ratio was produced due to the predominance of SRM and WGS reactions. Then, as expected, $\mathrm{CO}_{2}$ conversion increased with the increase of the temperature. At $800{ }^{\circ} \mathrm{C}$ and with a feed composition of $\mathrm{CH}_{4} / \mathrm{CO}_{2} / \mathrm{H}_{2} \mathrm{O} / \mathrm{O}_{2}=1 / 0.7 / 0.085 / 0.2$, high $\mathrm{CO}_{2}$ and $\mathrm{CH}_{4}$ conversions of respectively 86 and $99 \%$ and desired $\mathrm{H}_{2} / \mathrm{CO}$ ratio of 2.1 could be achieved without catalyst deactivation. In fact, this high temperature favored coke gasification as well as SRM and POM reactions to produce desired $\mathrm{H}_{2} / \mathrm{CO}$ ratio. At higher temperatures $\left(850{ }^{\circ} \mathrm{C}\right), \mathrm{CO}_{2}$ conversion increased by its reforming reaction with $\mathrm{CH}_{4}$, but $\mathrm{H}_{2} / \mathrm{CO}$ ratio decreased since WGS reaction is less favorable. At
$800{ }^{\circ} \mathrm{C}$ of operation, the catalyst surface area was decreased from 34.5-22.1 $\mathrm{m}^{2} \mathrm{~g}^{-1}$. However, this change did not affect the catalyst performance. In addition, the reduced $\mathrm{Ni}$ species in the cubic fluorite phase of the the $(\mathrm{Ni}, \mathrm{Mg}) \mathrm{O}$ solid solution are stable under TRM conditions.

The contributions highlighted above confirm that high temperature ( $>700{ }^{\circ} \mathrm{C}$ ) is required for TRM process to obtain high $\mathrm{CH}_{4}$ and $\mathrm{CO}_{2}$ conversions, high $\mathrm{H}_{2}$ yield, and to limit coke deposition. However, high reaction temperature also requires high energy supply and can cause catalyst deactivation due to sintering. The latter will be discussed in details in Section 4.

Recent advanced development in catalysis science, i.e. single atom catalyst (SAC), shows a possibility of performing methane reforming at relatively moderate temperatures (e.g. $\left.500^{\circ} \mathrm{C}\right)$. For instant, Duarte et al. [33] investigated SRM at $500{ }^{\circ} \mathrm{C}$ over Rh supported alumina catalysts (with or without cerium and/or samarium promoters). Three catalysts were synthesized and compared in SRM: $\mathrm{Rh} / \mathrm{Al}_{2} \mathrm{O}_{3}, \mathrm{Rh} / \mathrm{CeO}_{2}-\mathrm{Al}_{2} \mathrm{O}_{3}$, and $\mathrm{Rh} / \mathrm{Sm}_{2} \mathrm{O}_{3}-\mathrm{CeO}_{2}-\mathrm{Al}_{2} \mathrm{O}_{3}$. After $\mathrm{H}_{2}$ reduction at $600{ }^{\circ} \mathrm{C}$, all of them contained $\mathrm{Rh}$ isolated atoms, but with a fraction of small clusters between 0.3 and $1.1 \mathrm{~nm}$. In SRM at $760{ }^{\circ} \mathrm{C}, \mathrm{Rh} / \mathrm{Al}_{2} \mathrm{O}_{3}, \mathrm{Rh} / \mathrm{CeO}_{2}-\mathrm{Al}_{2} \mathrm{O}_{3}$, and $\mathrm{Rh} / \mathrm{Sm}_{2} \mathrm{O}_{3}-\mathrm{CeO}_{2}-\mathrm{Al}_{2} \mathrm{O}_{3}$ showed the specific reaction rate of $1.5,2.8$ and 1.8 (numbers of molecule site $\mathrm{s}^{-1} \mathrm{~s}^{-1}$ ), respectively, and the average deactivation rate after $48 \mathrm{~h}$ of time-on-stream of 40,17 and $33 \%$, respectively. High catalytic deactivation of $\mathrm{Rh} / \mathrm{Al}_{2} \mathrm{O}_{3}$ was due to $\mathrm{Rh}$ particle sintering. This latter is limited by $\mathrm{Ce}$ and $\mathrm{Ce}-\mathrm{Sm}$ promotion, which lowered the catalytic deactivation of the two promoted catalysts. The highest activity of $\mathrm{Rh} / \mathrm{CeO}_{2}-\mathrm{Al}_{2} \mathrm{O}_{3}$ is explained by the cooperative effect of $\mathrm{Rh}$ isolated atoms and $\mathrm{Rh}$ clusters on the surface of this catalyst. $\mathrm{Rh}$ isolated atoms favor $\mathrm{CH}_{4}$ activation, while $\mathrm{Rh}$ clusters favors solid
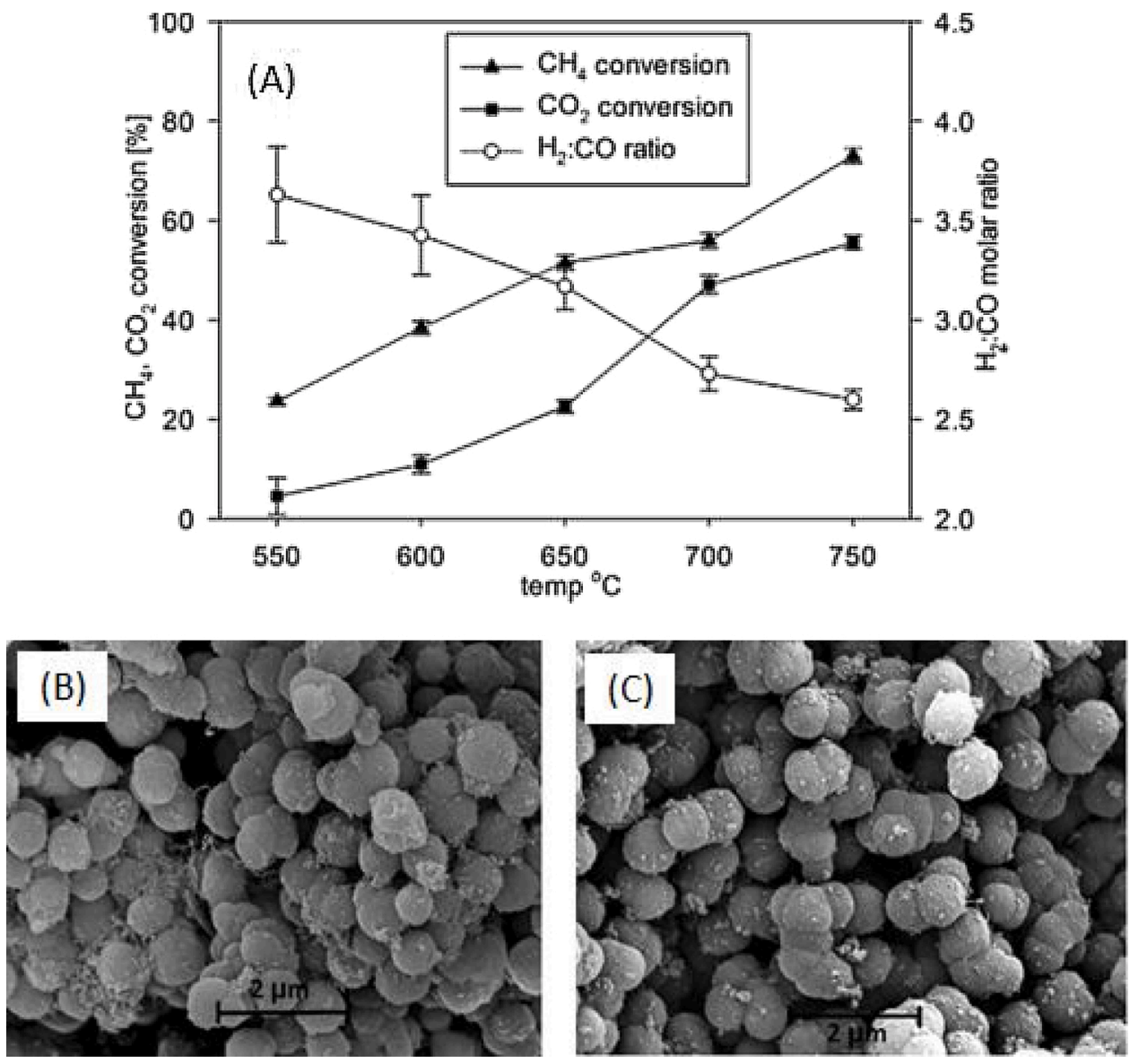

Fig. 4. TRM at $500-750{ }^{\circ} \mathrm{C}$ over $11 \% \mathrm{Ni} @ S i O_{2}$ catalyst (reaction conditions: Feed molar ratio $\mathrm{CH}_{4} / \mathrm{CO}_{2} / \mathrm{H}_{2} \mathrm{O} / \mathrm{O}_{2} / \mathrm{He}=1 / 0.5 / 0.5 / 0.1 / 0.4 ; \mathrm{CH}$ flowrate: $25 \mathrm{~mL} / \mathrm{min}$; $\mathrm{Ni} @ \mathrm{SiO}_{2}$ mass: $0.2 \mathrm{~g}$ ). (A) effect of reaction temperature on $\mathrm{CH}_{4}$ and $\mathrm{CO}_{2}$ conversion and $\mathrm{H}_{2} / \mathrm{CO}$ molar ratio; (B) and (C) SEM micrographs of the $11 \% \mathrm{Ni} @ \mathrm{SiO}{ }_{2}$ catalyst after $4 \mathrm{~h}$ of reaction at 550 and $750{ }^{\circ} \mathrm{C}$, respectively. Reprinted with permission from [31]. Copyright 2014 Elsevier. 
carbon gasification into $\mathrm{H}_{2}$ and CO. Thus, the co-existence of both Rh single atoms and Rh clusters was identified as an optimal recipe for SRM. Tang et al. [34] studied DRM at $500-600{ }^{\circ} \mathrm{C}$ over catalysts containing single atoms of both $\mathrm{Ni}$ and $\mathrm{Ru}$ supported on $\mathrm{CeO}_{2}$ nanorods. By experimental and DFT calculation, the authors revealed that the activation of $\mathrm{CH}_{4}$ and $\mathrm{CO}_{2}$ occurred and were promoted spontaneously on the single atoms of $\mathrm{Ni}$ and $\mathrm{Ru}$, respectively. The synergistic combination allowed reaching high $\mathrm{CH}_{4}$ conversion $(90 \%)$ and high $\mathrm{H}_{2}$ selectivity (nearly $100 \%$ ) at low temperature of $500-600{ }^{\circ} \mathrm{C}$ (reaction conditions: $50 \mathrm{mg}$ catalyst, total gas flowrate of $2000 \mathrm{~mL} \mathrm{~min}^{-1}$ containing $1 \% \mathrm{CH}_{4}$ and $1 \% \mathrm{CO}_{2}$ ). Interestingly, the single-atom sites of $\mathrm{Ni}$ and $\mathrm{Ru}$ was reported to remain in a cationic state during catalysis, which allow the low operating temperature of DRM. This new insight suggests a new approach to overcome another deactivation factor in TRM by re-oxidation of active phase, and merits further investigations. Note that to date, any work has been reported yet on the application of SAC in TRM. We believe that using metal isolated atoms with or without promoters constitutes a promising approach to lower operating temperature in TRM.

\subsection{Pressure}

As stated previously in Section 2.1, high pressure does not favor TRM reaction. While most laboratory work have been performed at atmospheric pressure, large scale processes usually operate at high pressure to favor downstream applications of syngas [18]. To date, only few experimental investigations in TRM were performed at high pressure [35-37]. In an early work, Zhao et al. [35] studied TMR at $800-860{ }^{\circ} \mathrm{C}$ and $1-6$ bar over $\mathrm{Ni} / \mathrm{Mg} / \mathrm{Ce}_{0.6} \mathrm{Zr}_{0.4} \mathrm{O}_{2} / \mathrm{Al}_{2} \mathrm{O}_{3}$ pellet catalysts (SI 1 ). In this pressure range, high $\mathrm{CH}_{4}$ conversion was obtained, which only slightly varied from 93 to $99 \%$. On the other hand, $\mathrm{CO}_{2}$ conversion was largely influenced by pressure at all temperatures investigated.
Especially, at $860{ }^{\circ} \mathrm{C}, \mathrm{CO}_{2}$ conversion increased from 4 to $61 \%$ as pressure increased from 1 to 6 bar. The increase of the total pressure also led to a decrease of the molar ratio of $\mathrm{H}_{2} / \mathrm{CO}$. The authors explained these results by the impact of the total pressure on the RWGS reaction [35]. This argument seems to be not really convinced since RWGS reaction is theoretically not impacted by the total pressure. In addition, the experimental results obtained in this work were contradictory compared to the thermodynamic prediction (Fig. 1). The authors did not precise the feed composition, in particularly the signification of $\mathrm{H}_{2} \mathrm{O} / \mathrm{CH}_{4}$ ratio at each temperature investigated.

In another work, TRM reaction was performed at 3 bar and $882{ }^{\circ} \mathrm{C}$ over cylindrical $\mathrm{NiMg} / \mathrm{Ce}_{0.6} \mathrm{Zr}_{0.4} \mathrm{O}_{2}$ pellet catalysts [36]. An increase of the inlet $\mathrm{H}_{2} \mathrm{O} / \mathrm{CH}_{4}$ molar ratio from 0.35 to 1.16 resulted in a reduction in $\mathrm{CO}_{2}$ conversion from 56 to $20 \%$, but an increase of the $\mathrm{H}_{2} / \mathrm{CO}$ molar ratio from 1.5 to 2.2. No comparison with other pressure was reported in this work [36].

Ren et al. [37] investigated TRM in the total pressure range of $1-10$ bar over a $\mathrm{Ni} / \mathrm{SiO}_{2}$ catalyst. Fig. 5 shows the results obtained at $750{ }^{\circ} \mathrm{C}$ for the equimolar feed composition $\mathrm{CH}_{4} / \mathrm{CO}_{2} / \mathrm{H}_{2} \mathrm{O} / \mathrm{O}_{2}=1.0 / 0.3 / 0.3 / 0.2$. At atmospheric pressure, both $\mathrm{CH}_{4}$ and $\mathrm{CO}_{2}$ conversions were relatively stable. Increasing the total pressure to 5 and $10 \mathrm{~atm}$ negatively impacted TRM reaction, leading to a decrease of $\mathrm{CH}_{4}$ and $\mathrm{CO}_{2}$ conversions, with a larger extent for $\mathrm{CO}_{2}$ than for $\mathrm{CH}_{4}$. The authors explained this result by the negative impact of the total pressure on DRM reaction. This latter is more negatively impacted by high total pressure than SRM and POM, due to the weaker oxidation of $\mathrm{CO}_{2}$ against $\mathrm{H}_{2} \mathrm{O}$ and $\mathrm{O}_{2}$ [37]. Thus, in view of a future deployment of TRM at large scale, the design of an efficient catalyst, capable to work at moderate temperature (e.g. $<700^{\circ} \mathrm{C}$ ) and high pressure (ca. $20 \mathrm{bar}$ ) is of crucial important.

In methane catalytic reforming, the formation of solid carbon is among the most important issues of the process, which causes the
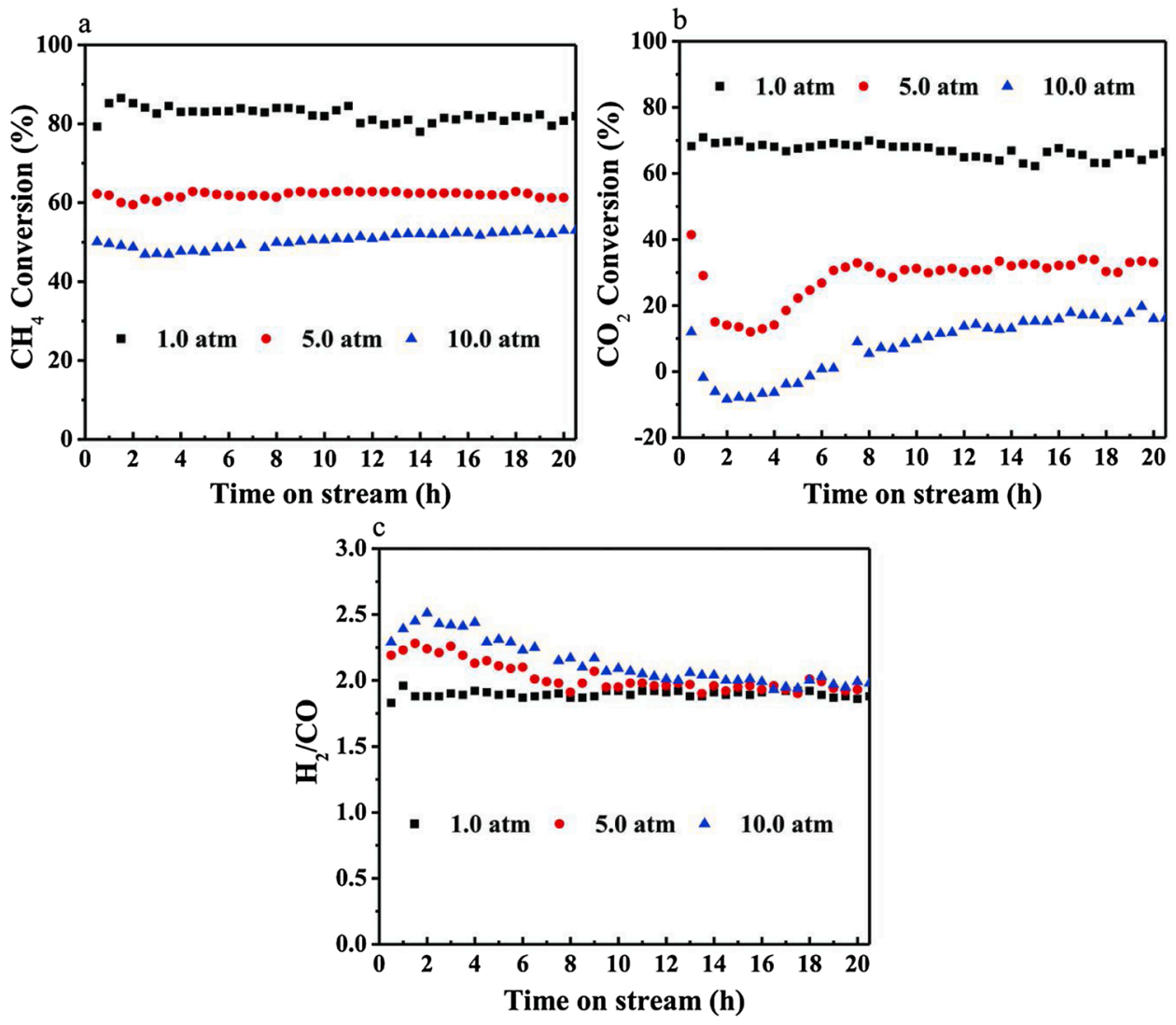

Fig. 5. Impact of the total pressure in $\mathrm{TRM}$ over $\mathrm{Ni} / \mathrm{SiO}_{2}$ catalyst at $750{ }^{\circ} \mathrm{C}$; feed molar ratio $\mathrm{CH}_{4} / \mathrm{CO}_{2} / \mathrm{H}_{2} \mathrm{O} / \mathrm{O}_{2}=1.0 / 0.3 / 0.3 / 0.2 ; \mathrm{GHSV}=26,600 \mathrm{~mL}\left(\mathrm{CH}{ }_{4}\right) \mathrm{g}^{-1} \mathrm{~h}^{-1}$. Reproduced with permission from [37]. Copyright 2015 Americal Chemical Society. 
catalyst deactivation together with the thermal sintering. As previously predicted by Phan et al. [19], in TRM reaction for a typical composition of a landfill gas, the formation of solid carbon cannot be theoretically avoided at $700{ }^{\circ} \mathrm{C}$ within $1-30$ bar, but can be theoretically avoided below 16 bar at $900{ }^{\circ} \mathrm{C}$ as shown in Fig. 6. However, to the best of our knowledge, the influence of the total pressure on the formation of solid carbon has not been experimentally studied yet. On the other hand, it has particularly been reported for DRM reaction where the formation of solid carbon is strongly favored by high pressure ( $>1$ bar) $[38,39]$. As partial conclusion, only few works have been dedicated to the experimental investigation of the impact of the total pressure in TRM, while operating at high pressure seems to be inevitable at large scale. More effort should be devoted on this part to better understand TRM process at high pressure.

\subsection{Feed composition}

As previously introduced (Section 1), TRM process combines three reactions of SRM, DRM and POM, each of them leads to a proper theoretical molar ratio of $\mathrm{H}_{2} / \mathrm{CO}$. Thus, by varying TRM feed composition, the final $\mathrm{H}_{2} / \mathrm{CO}$ ratio could be controlled, which is an indisputable advantage of TRM in comparison to the individual SRM, DRM and POM processes. However, the complex environment of TRM can also cause the catalyst deactivation due to metal re-oxidation and/or sintering. We discuss here the influence of feed composition on the individual reactions involved in TRM process, the conversion of methane and the oxidants, and then on the structure of the catalyst systems.

In TRM, since $\mathrm{CH}_{4}$ can react with one of the three oxidants, which are $\mathrm{O}_{2}, \mathrm{H}_{2} \mathrm{O}$, and $\mathrm{CO}_{2}$. Thus, a competition between these oxidants can take place when feed composition changes. According to the thermodynamic study of Zhang et al. [16], increasing the steam/methane molar ratio $\left(\mathrm{S} / \mathrm{C}\right.$ ) allows increasing $\mathrm{H}_{2} / \mathrm{CO}$ molar ratio, but decreases $\mathrm{CO}_{2}$ conversion. This was experimentally demonstrated by Izquierdo et al. [3]. In this work, TRM reaction was investigated at various $\mathrm{S} / \mathrm{C}$ ratios from 1.0-3.0, and $\mathrm{O}_{2} / \mathrm{CH}_{4}$ ratios of 0.25 and 0.50 , using different nickel-based catalysts. Under the conditions used, high $\mathrm{CH}_{4}$ conversions (> $95 \%$ ) were obtained. Thus, $\mathrm{CH}_{4}$ conversion could only slightly increase with the increase of the $\mathrm{S} / \mathrm{C}$ ratio. On the other hand, $\mathrm{CO}_{2}$ conversion strongly decreased by increasing $\mathrm{S} / \mathrm{C}$ ratio. This is explained by the WGS reaction, which converts $\mathrm{H}_{2} \mathrm{O}$ and $\mathrm{CO}$ into $\mathrm{CO}_{2}$ and $\mathrm{H}_{2}$. Accordingly, when the $\mathrm{S} / \mathrm{C}$ ratio increases, more water is available for promoting the WGS reaction. Consequently, more $\mathrm{CO}_{2}$ and $\mathrm{H}_{2}$ are produced while $\mathrm{CO}$ is consumed, which in turn increases the $\mathrm{H}_{2} / \mathrm{CO}$ ratio. Similar results were reported by Pino et al. [40] and Lo Faro et al. [41]. In addition to WGS, García-Vargas et al. [24] explained the effect of S/C ratio on the decrease of $\mathrm{CO}_{2}$ conversion by the competition of the three oxidants in methane reforming. According to these authors, $\mathrm{CO}_{2}$ is thermodynamically less reactive than $\mathrm{H}_{2} \mathrm{O}$ and $\mathrm{O}_{2}$ to reform $\mathrm{CH}_{4}$ in TRM. The authors also highlighted the importance of the WGS reaction in TRM. High $\mathrm{H}_{2} \mathrm{O}$ and low $\mathrm{CO}_{2}$ concentrations coupled with low temperatures represent the most favorable conditions for the WGS reaction, causing low $\mathrm{CO}_{2}$ conversion. Walker et al. [32] also stated that $\mathrm{H}_{2} \mathrm{O}$ adsorption blocks $\mathrm{CO}_{2}$ adsorption and thus inhibits $\mathrm{CO}_{2}$ reaction with $\mathrm{CH}_{4}$.

Several authors reported that increasing oxygen content in the feed leas to an increase of $\mathrm{CH}_{4}$ conversion, and a decrease of $\mathrm{CO}_{2}$ conversion [3,24,31,40-44]. At the TRM reactor outlet, oxygen concentration was usually reported to be equal to zero, indicating that it was totally consumed in TRM reaction [3,31]. This rapid $\mathrm{O}_{2}$ consumption is assigned to high affinity of oxygen with the metallic active sites [32]. For example, Majewski and Wood [31] studied TRM over $\mathrm{Ni} / \mathrm{SiO}_{2}$ catalyst at $750{ }^{\circ} \mathrm{C}$ using a feed composition as follows: $\mathrm{CH}_{4} / \mathrm{CO}_{2} / \mathrm{H}_{2} \mathrm{O} / \mathrm{O}_{2} / \mathrm{He}=1 / 0.5 / 0.5 / 0-0.5 / 0-0.5$. Thus, by increasing the molar ratio of $\mathrm{CH}_{4} / \mathrm{O}_{2}$ in the feed from $1 / 0-1 / 0.5, \mathrm{CH}_{4}$ conversion increased from ca. 70 to ca. $90 \%$, while $\mathrm{CO}_{2}$ conversion decreased from ca. 80 to $55 \%$. In parallel, the molar ratio of $\mathrm{H}_{2} / \mathrm{CO}$ also increased from ca. 2.3-2.6, and carbon deposition decreased. As mentioned above, $\mathrm{O}_{2}$ is considered as more reactive with $\mathrm{CH}_{4}$ than $\mathrm{H}_{2} \mathrm{O}$ and $\mathrm{CO}_{2}$. It reacts with $\mathrm{CH}_{4}$ by the partial or even total methane oxidation to produce syngas or a mixture of $\mathrm{CO}_{2}$ and $\mathrm{H}_{2} \mathrm{O}$, and thus impacts $\mathrm{CO}_{2}$ conversion. However, as a function of catalyst structure, increasing $\mathrm{O}_{2}$ content in the feed could lead to a negative impact on $\mathrm{CH}_{4}$ conversion, as reported by Solov'ev et al. [45]. Methane conversion decreased by adding $\mathrm{O}_{2}$ to the feed in TRM over $\mathrm{NiO} / \mathrm{Al}_{2} \mathrm{O}_{3}$ but increased when $\mathrm{NiO} / \mathrm{Al}_{2} \mathrm{O}_{3}-\mathrm{La}_{2} \mathrm{O}_{3}$ or $\mathrm{NiO} / \mathrm{Al}_{2} \mathrm{O}_{3}-\mathrm{CeO}_{2}$ were used [45]. In fact, depending on the operating conditions, the metallic active phase of the catalyst bed could undergo a re-oxidation, thus impacts the reforming activity of the catalyst. The re-oxidation of the active phase will be specifically discussed in the section 4.3.2.

Pino et al. [46] investigated the influence of $\mathrm{CH}_{4} / \mathrm{CO}_{2}$ molar ratios (1.04-2.47) on the TRM performance over a series of $\mathrm{Ni} / \mathrm{La}-\mathrm{Ce}-\mathrm{O}$ mixed oxides catalysts. They showed that at low $\mathrm{CH}_{4} / \mathrm{CO}_{2}$ ratios (lower than 2.26), all catalysts had stable performances, with a progressive increase in the $\mathrm{CH}_{4}$ and $\mathrm{CO}_{2}$ conversions rates by increasing the $\mathrm{CH}_{4} / \mathrm{CO}_{2}$ ratio in the feed. When this ratio increased to 2.47 , light deactivations were observed along the time on stream for all the catalysts. In addition, the authors showed that the $\mathrm{H}_{2} \mathrm{O}$ conversion rate followed the same trend of the $\mathrm{CH}_{4}$ and $\mathrm{CO}_{2}$ conversion rates: increases by increasing the $\mathrm{CH}_{4} / \mathrm{CO}_{2}$ ratio, but the moles of converted steam result lower than the $\mathrm{CH}_{4}$ and $\mathrm{CO}_{2}$ reacted. These observations suggest the simultaneous occurrence of RWGS reaction with reforming reactions [46].

Feed composition strongly affects the performance of TRM process.
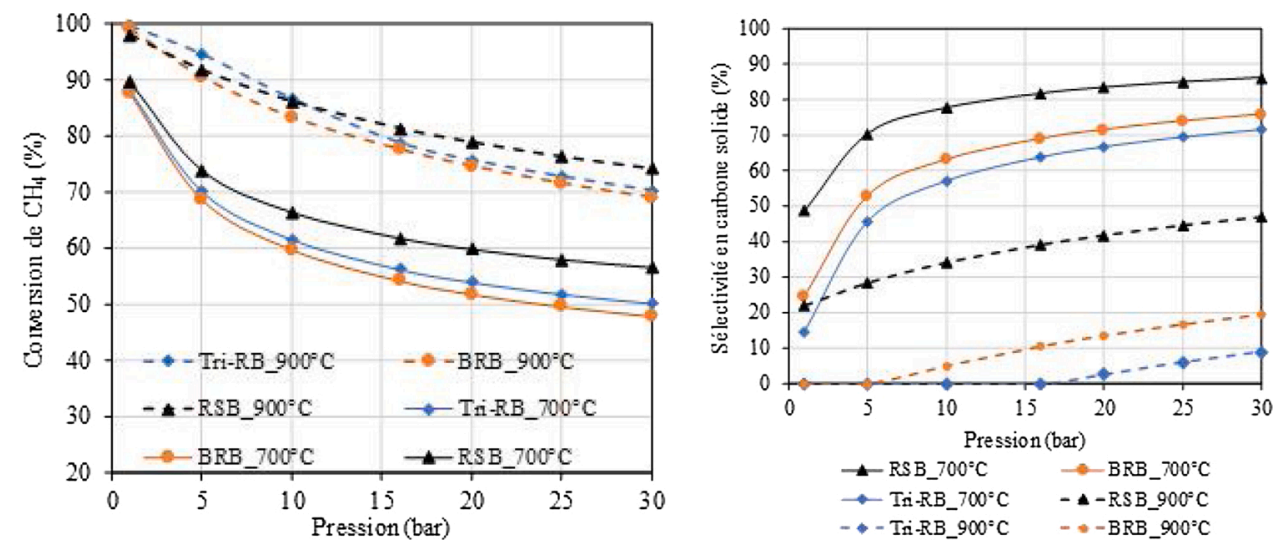

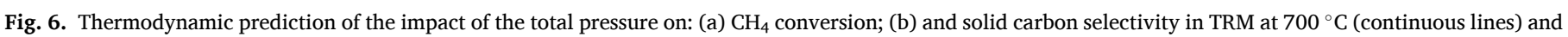

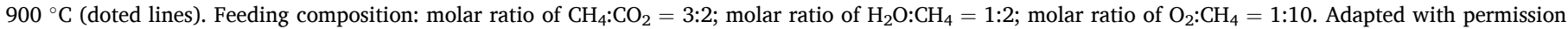
from [19]. 
Thermodynamically, increases in $\mathrm{O}_{2}$ and $\mathrm{H}_{2} \mathrm{O}$ contents in the feed enhance $\mathrm{CH}_{4}$ conversion and carbon deposition elimination but reduce of both $\mathrm{CO}_{2}$ conversion and $\mathrm{H}_{2}$ yield [16]. To obtain the optimum feed ratios in TRM, the objective is to maximize the $\mathrm{H}_{2}$ yield, considering the following three constraints: (1) the conversion of $\mathrm{CO}_{2}$ should be higher than $90 \%$; (2) the $\mathrm{H}_{2} / \mathrm{CO}$ ratio should be higher than 2.0 , which is a desirable value for downstream synthesis reactions, such as methanol synthesis or Fischer - Tropsch reactions; and (3) the solid carbon formation is forbidden during reactions. For example, Zhang et al. [16] proposed an optimum feed ratio for TRM is $\mathrm{CH}_{4} / \mathrm{CO}_{2} / \mathrm{H}_{2} \mathrm{O} / \mathrm{O}_{2}=1: 0.291: 0.576: 0.088$. The results showed that the $\mathrm{H}_{2}$ yield reached a maximum of $94.5 \%$, with more than $90 \%$ of $\mathrm{CO}_{2}$ conversion and $\mathrm{H}_{2} / \mathrm{CO}$ ratio equal to 2.0. Also, carbon formation was found to be suppressed under the optimized operating variables.

Regarding the influence of feed composition on the structure of the catalyst system, several works have identified the negative impact of water content causing the sintering [15], and the negative impact of oxygen content causing the re-oxidation of metal nanoparticles [30]. These points will be addressed in Section 4.

As partial conclusions, feed composition is a very important parameter to adjust the final molar ratio of $\mathrm{H}_{2} / \mathrm{CO}$ and to limit coke formation. A competition between $\mathrm{O}_{2}, \mathrm{H}_{2} \mathrm{O}$ and $\mathrm{CO}_{2}$ exists for $\mathrm{CH}_{4}$ reforming, and $\mathrm{O}_{2}$ is firstly consumed. Taking into account the fact that active phase could be re-oxidized during TRM, it is recommended to work with low $\mathrm{O}_{2}$ contents in the feed (e.g. $\leq 5 \%$ vol.) which fit with its composition in a given biogas, landfill gas, or flue gas. It is also recommended to work with the molar ratio of $\left(\mathrm{O}_{2}+\mathrm{H}_{2} \mathrm{O}+\mathrm{CO}_{2}\right) / \mathrm{CH}_{4}$ slightly higher than the stoichiometry to optimize energy balance [19].

\subsection{Gas hourly space velocity}

Gas hourly space velocity (GHSV, $\mathrm{mL} \mathrm{h}^{-1} \mathrm{~g}^{-1}$ ) is another operating parameter which can influence TRM performance. This parameter indicates the relative between the volumetric flowrate of the feedstock and mass of catalyst used. In some cases, weight hourly space velocity (WHSV, $\mathrm{h}^{-1}$ ), which refers to the ratio of mass of the feed per hour to the mass of the catalyst can also be used. It is reported that GHSV affects TRM performance through two mechanisms: (i) increasing or reducing the contact time between the reactants and catalyst and (ii) determining temperature distribution within catalyst bed. In detail, Sun et al. [42] investigated the effect of GHSV on the reaction performances using $0.2 \mathrm{~g}$ of Ni/SBA-15 catalyst. Their results are presented in Fig. 7. It was observed that both the $\mathrm{CH}_{4}$ and $\mathrm{CO}_{2}$ conversions declined, and the $\mathrm{H}_{2} / \mathrm{CO}$ molar ratio of the product increased with the increase of GHSV.

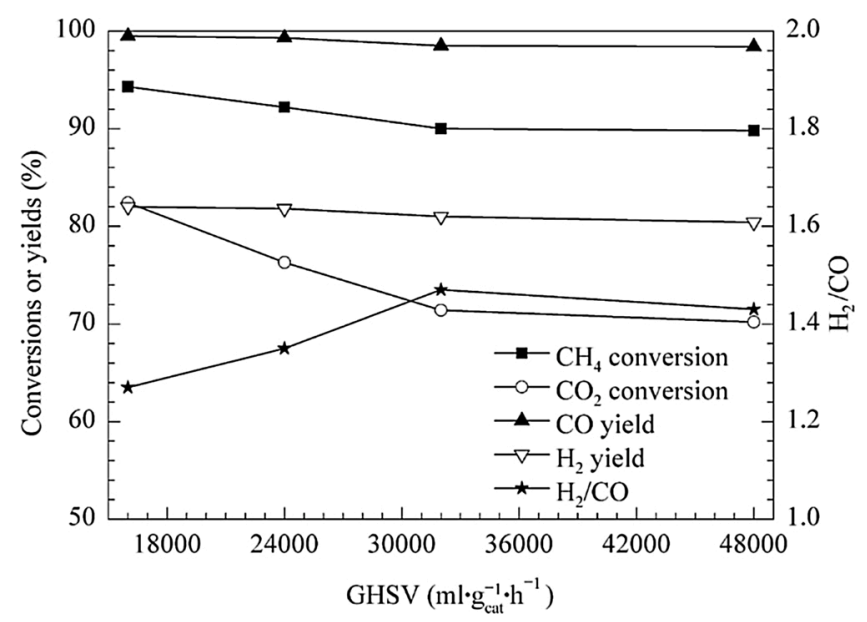

Fig. 7. Effect of GHSV on the reaction performances of $10 \mathrm{wt} \% \mathrm{Ni} / \mathrm{SBA}-15$ catalyst. Reaction conditions: $\mathrm{CH}_{4} / \mathrm{CO}_{2} / \mathrm{O}_{2} / \mathrm{H}_{2} \mathrm{O}=2 / 1 / 0.6 / 0.6 ; \mathrm{T}=800{ }^{\circ} \mathrm{C}$; catalyst 0.2 g. Reprinted with permission from [42], Copyright 2010 Elsevier.
The $\mathrm{CH}_{4}$ conversion decreased from $94.3 \%-90.0 \%$ and the $\mathrm{CO}_{2}$ conversion decreased from $82.4 \%-71.4 \%$ when the GHSV increased from 16,000 to $32,000 \mathrm{~mL} \mathrm{~h}^{-1} \mathrm{~g}^{-1}$. In addition, the $\mathrm{H}_{2} / \mathrm{CO}$ molar ratio increased from 1.27 to 1.47 . When the GHSV exceeded $32,000 \mathrm{~mL}$ $\mathrm{h}^{-1} \mathrm{~g}^{-1}$, there was no obvious change in these three parameters. In addition, $\mathrm{H}_{2}$ and $\mathrm{CO}$ yields kept invariant with the increase of GHSV, and $\mathrm{H}_{2}$ yield and $\mathrm{CO}$ yield maintained at $81.0 \%$ and $99.0 \%$, respectively. The author explained that the contact time between the reactants and catalyst reduced with the increase of GHSV. So, the adsorption and activation of reactant molecule decreased. Meanwhile, the real temperature of the catalyst bed will be lowered since more reactants will enter the reactor with a higher GHSV. This also leads to a decrease in the $\mathrm{CH}_{4}$ and $\mathrm{CO}_{2}$ conversions.

At moderate $\mathrm{CH}_{4}$ and $\mathrm{CO}_{2}$ conversions (52-78 \%), Kozonoe et al. [47] found that decreasing GHSV allowed increasing both $\mathrm{CH}_{4}$ and $\mathrm{CO}_{2}$ conversions over 5\%Ni@MWCNT/5\%Ce catalysts. Similar results were obtained by Jiang et al. [48], who investigated TRM over $\mathrm{Ni} / \mathrm{Al}_{2} \mathrm{O}_{3}$ catalyst. They indicated that both the conversions of $\mathrm{CH}_{4}$ and $\mathrm{CO}_{2}$ decreased with the increase in GHSV, and the $\mathrm{CO}_{2}$ conversion decreased more steeply than that of $\mathrm{CH}_{4}$. At high GHSV, the exothermic $\mathrm{COM}$ and $\mathrm{POM}$ reactions continue at a high rate, whereas the endothermic reforming reactions with relative slow rate may be incomplete. On the other hand, the flowing gas brings heat from the inlet to the outlet in the catalyst bed; increasing GHSV will enhance heat transfer. Singha et al. [49] investigated the influence of GHSV in TRM over $\mathrm{Ni} / \mathrm{CeO}_{2}-\mathrm{ZrO}_{2}$ catalysts at $800{ }^{\circ} \mathrm{C}, 1$ atm, with feed composition of $\mathrm{O}_{2} / \mathrm{CO}_{2} / \mathrm{H}_{2} \mathrm{O} / \mathrm{CH}_{4} / \mathrm{He}=1 / 1 / 2.1 / 5 / 18$. Once again, they found that increasing GHSV from $20,000-200,000 \mathrm{~mL} \mathrm{~h}^{-1} \mathrm{~g}^{-1}$ lowered $\mathrm{CH}_{4}, \mathrm{CO}_{2}$ and $\mathrm{H}_{2} \mathrm{O}$ conversions from 95,94 and $96 \%$ to respectively 68,62 and 64 $\%$. In parallel, the molar ratio of $\mathrm{H}_{2} / \mathrm{CO}$ decreased from 2.1 to around 2.0 [49].

Walker et al. [32] investigated the influence of WHSV on the TRM performance by varying the amount of catalyst used. They showed that high WHSV $\left(61,000 \mathrm{~h}^{-1}\right)$ yielded significantly higher $\mathrm{H}_{2} / \mathrm{CO}$ ratios when compared to reactions run at lower WHSV $\left(25,000 \mathrm{~h}^{-1}\right)$. By reducing the WHSV from $61,000-21,000 \mathrm{~h}^{-1}$, the $\mathrm{CH}_{4}$ and $\mathrm{CO}_{2}$ conversions were slightly lowered, while the $\mathrm{H}_{2} / \mathrm{CO}$ ratios were significantly reduced. The authors explained that the feed gas initially reacted and created higher $\mathrm{H}_{2}$ concentration. Thus, the RWGS reaction became more favorable further down the catalyst bed. This suggests that steam reforming reactions are kept further from equilibrium at higher WHSV and result in higher than expected $\mathrm{H}_{2}$ production at lower steam ratios.

As partial conclusions, GHSV (or WHSV) directly impacts the performance of TRM reaction. Low GHSV favors reactant conversions, but can also reduce syngas production rate. A compromise between GHSV, reactant conversions, and syngas production rate must be found to determinate the appropriate reaction conditions. The development of highly-performing TRM catalysts which efficiently work at high GHSV (or WHSV) should be targeted.

\section{Catalyst deactivation and regeneration}

The long-term stability of a catalytic heterogeneous system is always the challenging issue for implementing TRM technology in industrial application, which is generally associated with the degree of catalyst deactivation. Typically, catalyst deactivation in TRM could be attributed to several main factors, namely, (i) carbon deposition, (ii) thermal degradation, (iii) vapor-solid and/or solid-solid reactions, (iv) the confinement and coverage of active phases and (v) catalyst poisoning $[14,50]$. Although catalyst deactivation is unavoidable in methane reforming reaction, its immediate and adverse influences can be largely alleviated or counteracted via regeneration process. In recent years, researchers have devoted efforts to study the catalyst deactivation with the sole aim of providing an essential understanding for improving the catalyst design and regenerating catalyst in TRM process. In this section, a comprehensive discussion regarding deactivation processes and the 
corresponding regeneration or prevention methods in TRM is provided.

\subsection{Carbon and coke deposition}

In methane reforming, carbon and coke are generally referred as a result of the corresponding $\mathrm{CO}_{2}$ disproportionation and decomposition of polymerized long-chain hydrocarbons [14,50], which lead to blockage of active sites, surface and porosity on catalyst causing a loss in catalytic performance $[14,50]$. To facilitate discussions in this paper, the term "solid carbon" is used, covering both carbon and coke. As TRM is a
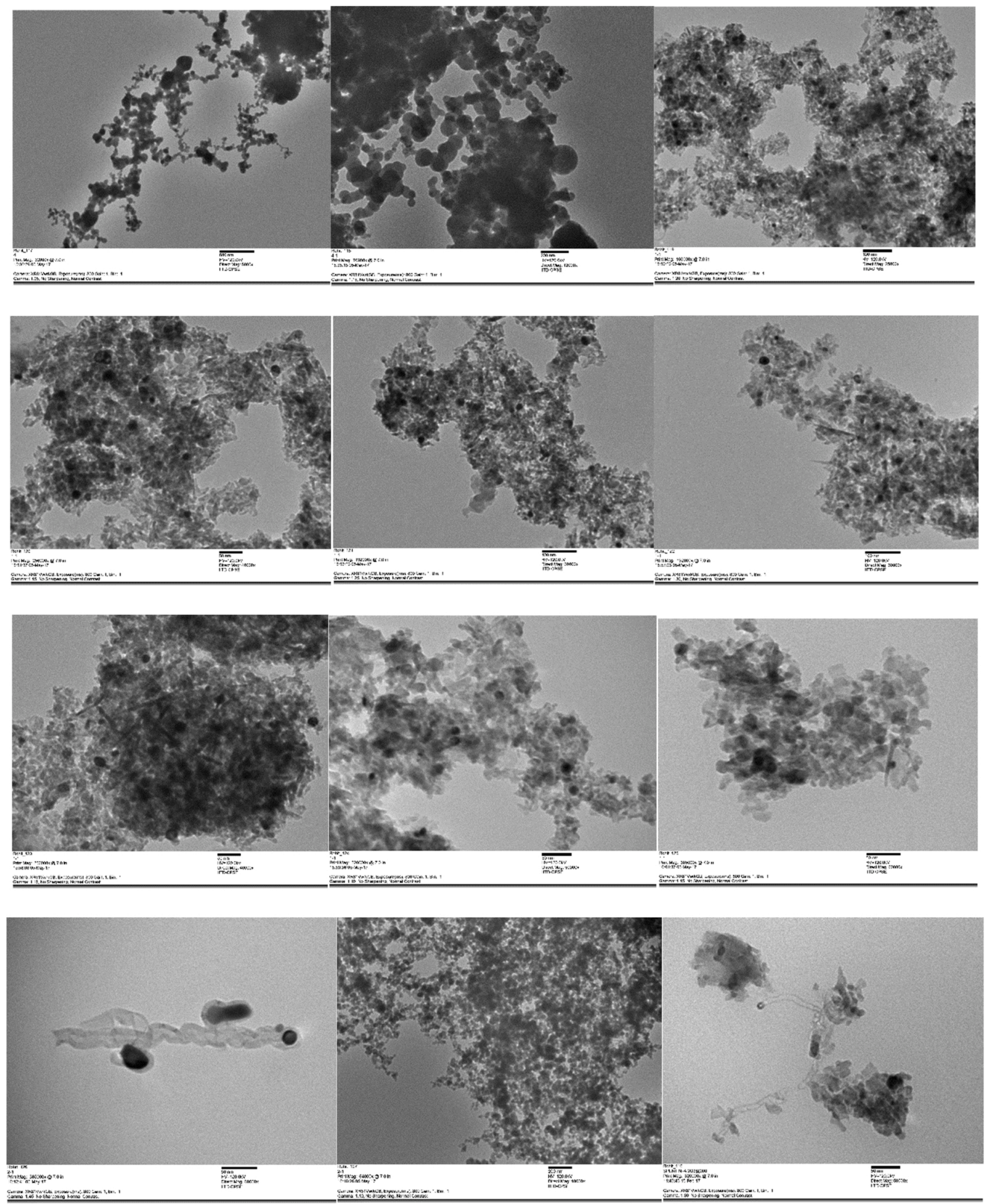

Fig. 8. TEM images of spent $\mathrm{Ni} / \mathrm{Al}_{2} \mathrm{O}_{3}$ catalyst after $10 \mathrm{~h}$ time on stream of TRM study (reactions conditions: $\mathrm{CH}_{4}: \mathrm{CO}_{2}: \mathrm{H}_{2} \mathrm{O}: \mathrm{O}_{2}: \mathrm{N}_{2}=1: 0.23: 0.46: 0.07: 0.28$, GHSV $=17,220 \mathrm{~mL} \mathrm{~h}^{-1} \mathrm{~g}^{-1}$, Temp. $800{ }^{\circ} \mathrm{C}$ at 1 bar). Reproduced with permission from [52], Copyright 2018 Elsevier. 
complex system consisting of multiple reactions, solid carbon deposition can occur simultaneously and be controlled through following equations:

Methane cracking:

$\mathrm{CH}_{4} \Leftrightarrow \mathrm{C}+2 \mathrm{H}_{2} \quad \Delta H_{298}^{0}=74.9 \quad \mathrm{~kJ} \cdot \mathrm{mol}^{-1}$

Boudouard reaction:

$2 \mathrm{CO} \Leftrightarrow \mathrm{C}+\mathrm{CO}_{2} \quad \Delta H_{298}^{0}=-172.2 \quad \mathrm{~kJ} \cdot \mathrm{mol}^{-1}$

Steam gasification of carbon:

$\mathrm{C}+\mathrm{H}_{2} \mathrm{O} \Leftrightarrow \mathrm{CO}+\mathrm{H}_{2} \quad \Delta H_{298}^{0}=131.4 \quad \mathrm{~kJ} \cdot \mathrm{mol}^{-1}$

Carbon dioxide gasification of carbon:

$\mathrm{C}+\mathrm{CO}_{2} \Leftrightarrow 2 \mathrm{CO} \quad \Delta H_{298}^{0}=172.2 \mathrm{~kJ} \cdot \mathrm{mol}^{-1}$

Water-gas shift reaction:

$\mathrm{CO}+\mathrm{H}_{2} \mathrm{O} \Leftrightarrow \mathrm{H}_{2}+\mathrm{CO}_{2} \quad \Delta H_{298}^{0}=-41 \quad \mathrm{~kJ} \cdot \mathrm{mol}^{-1}$

Complete carbon oxidation:

$\mathrm{C}+\mathrm{O}_{2} \Leftrightarrow \mathrm{CO}_{2} \quad \Delta H_{298}^{0}=-393.7 \mathrm{~kJ} \cdot \mathrm{mol}^{-1}$

Generally, solid carbon deposits on catalyst surface can be classified into three types, namely, carbolic carbon $(\alpha-C)$, amorphous carbon ( $\beta-C$ ) and graphitic carbon $(\gamma-C)$. The degree of graphitization is highly relating to the location between carbon atom and metal nanoparticles. The carbon atoms located in close vicinity of metal nanoparticles have higher tendency to undergo graphitization forming graphitic carbon, which is difficult to be removed in comparison with carbolic and amorphous carbons [51]. In fact, graphitic carbon $(\gamma-\mathrm{C})$ can exist in various forms such as coating carbon, carbon nanofiber and carbon nanotube. Fig. 8 shows an example of the carbon deposits on a Ni/ $/ \mathrm{Al}_{2} \mathrm{O}_{3}$ catalyst in TRM at $800{ }^{\circ} \mathrm{C}$ after $10 \mathrm{~h}$-on-stream [52]. Notably, the filamentous carbon with amorphous nature encapsulating the Ni particles was clearly evidenced in TEM images.

Fundamentally, carbon deposits on the catalyst surface can (i) partially or completely encapsulate active phase; (ii) block approachability of reactants to active sites, (iii) clog micro- and mesopores result in a hindrance of accessibility of reactant to the active phase located inside these pores. The formation of filamentous carbon is facilitated at higher temperature as carbon atoms readily diffuses through the lattice structure of Ni particles and continuously nuclearize to form as filaments from the back side, eventually pushes the Ni particles off the support surface, as seen in Fig. 8. Filamentous carbon usually encapsulates Ni particles hindering the exposure to gaseous reactants during reaction, eventually resulting in attrition of catalyst pellets and plugging of reactor void space [52].

As TRM is a complex system providing an oxidant-enriched surrounding, the adverse effect of carbon deposition on the TRM performance is expectedly to be addressed [6]. Kumar et al. [53] investigated the deactivation over Ni-based pyrochlore catalyst in several methane reforming reactions including: dry-reforming $\left(\mathrm{CH}_{4}: \mathrm{CO}_{2}=50: 50\right.$, mol $\%)$, bi-reforming $\left(\mathrm{CH}_{4}: \mathrm{CO}_{2}: \mathrm{H}_{2} \mathrm{O}=16: 51: 33\right.$, mol \%), and oxy-reforming $\left(\mathrm{CH}_{4}: \mathrm{CO}_{2}: \mathrm{O}_{2}=20: 60: 20, \mathrm{~mol} \%\right)$. Experiments were performed at $750{ }^{\circ} \mathrm{C}, 1 \mathrm{~atm}$ pressure and GHSV $=96000-100000 \mathrm{scc} \mathrm{h}^{-1} \mathrm{~g}_{\text {cat. }}^{-1}$ They found that carbonaceous deposition on catalyst surface was the main factor accounting for deactivation in the cases of dry-reforming and oxy-reforming. Particularly, the degree of deactivation as a function of time-on-stream reaction process reduced in following order: dry reforming $>$ oxy-reforming $>$ bi-reforming. Given the degree of catalyst deactivation is highly depending on the nature of carbon deposit, TPO analyses (Fig. 9) were performed, which revealed that graphitic carbon was largely produced under dry-reforming whereas in oxy-reforming, a majority of the carbon deposit was the amorphous carbon. Interestingly, no characteristic peaks corresponded to carbon deposit was observed from the TPO measurement for bi-reforming case, indicating that total

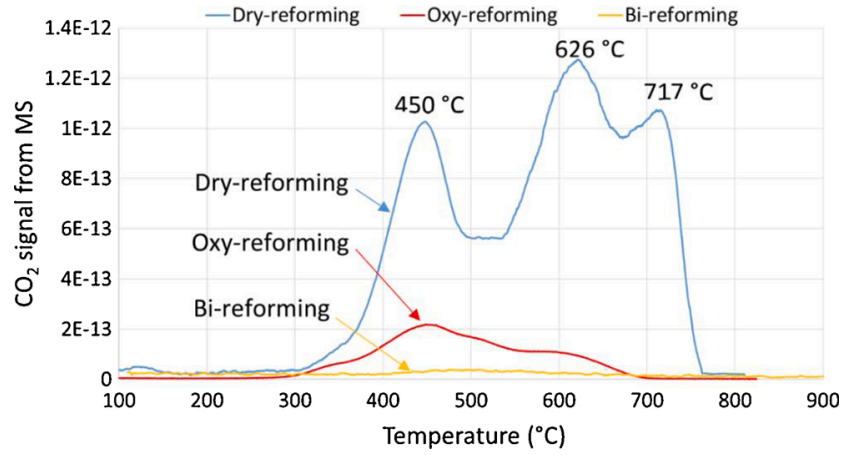

Fig. 9. Temperature program oxidation results for spent catalysts from different reactions. Reaction conditions: $750{ }^{\circ} \mathrm{C}, 1 \mathrm{~atm}$ and GHSV $=96,000$ $100,000 \mathrm{scc} \mathrm{h}^{-1} \mathrm{~g}_{\text {cat }}^{-1}$; dry-reforming (molar ratio of $\mathrm{CH}_{4}: \mathrm{CO}_{2}=50: 50, \mathrm{~mol} \%$ ), oxy-reforming (molar ratio of $\mathrm{CH}_{4}: \mathrm{CO}_{2}: \mathrm{O}_{2}=20: 60: 20$, mol \%) and bi-reforming (molar ratio of $\mathrm{CH}_{4}: \mathrm{CO}_{2}: \mathrm{H}_{2} \mathrm{O}=16: 51: 33$, mol \%). Reprinted from [53] (open access article distributed under the terms of the Creative Commons CC BY license).

removal of carbon deposit through gasification is viable under oxidant-rich environment, thus regenerating the active sites of catalyst. In addition, the structure of the catalyst did not change after catalysis under the three conditions, which is attributed to high dispersion of $\mathrm{Ni}$ particles, high thermal stable of pyrochlore crystalline structure and high interaction between $\mathrm{Ni}$ and support.

The catalyst deactivation due to carbonaceous deposition can be solved or alleviated in the presence of highly active oxidizing agents (viz., $\mathrm{O}_{2}, \mathrm{CO}_{2}$ and $\mathrm{H}_{2} \mathrm{O}$ ), which efficiently hinders the nucleation process of carbon atoms. However, it also tends to induce re-oxidation of hosting metallic phase on catalyst resulting in a reduction in catalytic performance. In the investigation of metal-support interaction of Ni-based catalysts for TRM (reaction conditions: tubular reactor, at $800{ }^{\circ} \mathrm{C}$, 1 bar, GHSV $=17,220 \mathrm{~mL} \mathrm{~h}^{-1} \mathrm{~g}^{-1}$, molar ratio of $\mathrm{CH}_{4}: \mathrm{CO}_{2}: \mathrm{H}_{2} \mathrm{O}: \mathrm{O}_{2}$ : $\mathrm{N}_{2}=$ 1:0.23:0.46:0.07:0.28, TOS $=10 \mathrm{~h}$ ), Kumar et al. [51,52] reported that the Ni/SBA-15 possessed excellent resistance towards carbon deposition and great confinement governing the TRM performance with time-on-stream but re-oxidation of partial metallic $\mathrm{Ni}$ to $\mathrm{NiO}$ was unavoidable, as evidenced by XRD analyses. Such observation is in accordance with the findings of Kim et al. in their study of TRM over $\mathrm{NiCe} @ \mathrm{SiO}_{2}$ catalysts [77]. The TRM reaction was carried out in a fixed bed reactor at atmospheric pressure, using $75 \mathrm{mg}$ catalyst, GHSV of 60 , $000 \mathrm{~mL} \mathrm{~g}^{-1} \mathrm{~h}^{-1}$ at different $\mathrm{O} / \mathrm{M}$ feed molar ratios, TOS of $20 \mathrm{~h}$. They assigned the deactivation of $\mathrm{NiCe} @ \mathrm{SiO}_{2}$ to re-oxidation of the metallic $\mathrm{Ni}$ form deteriorating the multi-yolk-shell nanotube configuration under high feed ratio of oxidizing agents. In addition, they found that the rate of carbon oxidation was higher than that of carbon formation over $\mathrm{NiCe} @ \mathrm{SiO}_{2}$, thus the insufficiency of carbon deposit on catalyst surface causing the higher tendency of re-oxidation from metallic $\mathrm{Ni}$ to $\mathrm{NiO}$, thus causing catalyst deactivation. The re-oxidation of active metallic phase under extremely oxidative environment will be further discussed in section 4.3.2. In summary, the formation of solid carbon is generally favored under the conditions employed for TRM reaction. It is identified as a main reason causing the catalyst deactivation in TRM. The removal of solid carbon can be done using oxidizing agents such as $\mathrm{O}_{2}, \mathrm{H}_{2} \mathrm{O}$ and/or $\mathrm{CO}_{2}$, but it must take into consideration the risk of re-oxidation of the active phase.

As TRM is performed under high temperature and strongly oxidative surrounding, one of the efficient ways to remove the coke deposit is to gasify it using oxidizing agents (i.e., $\mathrm{O}_{2}, \mathrm{CO}_{2}$ and $\mathrm{H}_{2} \mathrm{O}$ ). The diffusivity and mobility of oxygen ions play an essential role at controlling the equilibrium between rate of gasification and rate of carbon formation. Thus, the capability of catalyst support to store oxygen atoms at oxidizing environment and release oxygen atoms under reducing surrounding, known as redox cycling, is an important feature prevailed for 
TRM redox catalyst [54]. In general, promoter and support materials such as Ce and La with high oxygen storage capacity (OSC) can facilitate the mobility of oxygen atoms from lattice to the surface when combined with the hosting active metals, thus promoting the redox cycling process [55-57]. The existence of redox cycle reportedly enhanced the activation of oxidants, hence promoting the oxygen coverage on catalyst surface and metal-support interaction, thereby reducing the amount of carbon deposit [58,59]. In an effort of improving the OSC of redox material, Shen et al. [60] prepared a double perovskite-type oxides $\mathrm{LaFe}_{\mathrm{x}} \mathrm{Co}_{1-\mathrm{x}} \mathrm{O}_{3}$ catalysts and examined their catalytic behavior under oxidant-enriched atmosphere (similar to TRM environment). By utilizing the redox cycling feature of the perovskite (Fig. 10), the syngas yield could be maximized meanwhile effectively suppressed the carbon deposit. The $\mathrm{CH}_{4}$ initially reacted with the adsorbed oxygen (total oxidation of $\mathrm{CH}_{4}$ ) and lattice oxygen (partial oxidation of $\mathrm{CH}_{4}$ ) in the $\mathrm{LaFe}_{\mathrm{x}} \mathrm{Co}_{1-\mathrm{x}} \mathrm{O}_{3}$ to form syngas and subsequently left abundancy of oxygen vacancy and $\mathrm{LaFe}_{\mathrm{x}} \mathrm{Co}_{1-\mathrm{x}} \mathrm{O}_{3}$ in reducible form with deposited carbon. In the $\mathrm{CO}_{2}$ purging stage, the oxygen atoms were captured by oxygen vacancies and restored the $\mathrm{LaFe}_{\mathrm{x}} \mathrm{Co}_{1-\mathrm{x}} \mathrm{O}_{3}$ back into oxide form whilst deposited carbon was oxidized to form $\mathrm{CO}$ during the process. This behavior allowed the $\mathrm{LaFe}_{\mathrm{x}} \mathrm{Co}_{1-\mathrm{x}} \mathrm{O}_{3}$ to achieve $\mathrm{H}_{2}$ selectivity of $99.6 \%$ and $\mathrm{CO}$ selectivity of $52.6 \%$, lasted for 10 cycles of reaction runs.

Along with the OSC, acido-basic character of a catalyst system has also been identified to be an important parameter to promote the gasification of the carbon solid. Indeed, a high concentration of basic sites was reported to enhance the adsorption of the acidic oxidant $\mathrm{CO}_{2}$ molecules onto the catalyst's surfaces. The subsequent adsorbed $\mathrm{CO}_{2}$ molecules further react with neighboring carbon atom to form $\mathrm{CO}$ gas and thus regeneration of the active sites for surface reaction [61-63]. Lino et al. [74] studied various $\mathrm{X}-\mathrm{ZrO}_{2}$ addition ( $\mathrm{La}, \mathrm{Ce}, \mathrm{Sm}, \mathrm{Y}$ ) on $\mathrm{Ni} / \mathrm{M}$ $\mathrm{gAl}_{2} \mathrm{O}_{4}$ for TRM by using advanced characterization techniques. Interestingly, the in-situ XANES and XPS results revealed that only moderate basicity contributed to the improvement of TRM activity by suppressing carbon formation and contrarily, a high density of basic sites strongly bind with $\mathrm{CO}_{2}$ making it unavailable for carbon gasification process, thus a decline in reactant conversions. In comparison to strong basicity, moderate basic sites (hydroxyls and $\mathrm{M}^{\mathrm{n}+}-\mathrm{O}^{-2}$ pairs) reportedly played a crucial role to enhance the surface reaction after activation of reactants, particular to the case of $\mathrm{CH}_{4}$ adsorption sites (metallic phase) that are closer to the $\mathrm{CO}_{2}$ adsorption sites (metal-support interface). With this finding, Lino et al. [54] further evaluated the Ce- $\mathrm{Zr}$ interaction on $\mathrm{Ni} / \mathrm{MgAl}_{2} \mathrm{O}_{4}$ for TRM and suggested that the degree of graphitization was dependent on the extent of basicity strength in a catalyst. The embedment of $\mathrm{Ce}$ and $\mathrm{Zr}$ modified the basic site distribution which reduced the quantity of disordered filamentous carbon on catalyst surface without declining the total carbon conversion $\left(\mathrm{CO}_{2}+\mathrm{CH}_{4}\right)$. The disordered coke was reactive to react with oxidant to form $\mathrm{CO}$ or $\mathrm{CO}_{2}$, which can be readily removed by gasification process. Such speculation was further corroborated in their works about tuning concentration of basic site by adjusting Zr/Ce molar ratio for TRM [64]. Similar finding on the positive impact of basic sites on carbon limitation was reported by other authors $[40,52,65]$.

Downsizing the active phase of TRM catalysts is another approach to overcome carbon deposition issues. Recent studies provide both experimental and theoretical analyses to proof the role of low coordinated surface active sites, i.e. nanoclusters and single atoms in the intrinsic limitation of the carbon solid formation [33,34,66,67]. Accordingly, these low coordinated surface sites can take part in binding toward the intermediates, lowering reaction barriers, changing the reaction pathway. For example, Akri et al. [67] successfully prepared Ni/HAP-Ce catalysts with highly active and carbon-resistant sites for DRM (conditions: $750{ }^{\circ} \mathrm{C}, 1 \mathrm{~atm}$, molar ratio of $\mathrm{CH}_{4}: \mathrm{CO}_{2}: \mathrm{He}=10: 10: 30$, total gas flowrate $=50 \mathrm{~mL} \mathrm{~min}^{-1}$, GHSV $=60,000 \mathrm{~mL} \mathrm{~h}^{-1} \mathrm{~g}_{\text {cat }}^{-1}$ ). Due to the atomically dispersed $\mathrm{Ni}$ atoms, only first $\mathrm{C}-\mathrm{H}$ bond in $\mathrm{CH}_{4}$ molecules was cleavage which prevented the further $\mathrm{CH}_{4}$ dissociation forming carbon atom based on their DFT calculation. Moreover, the Ce dopant created a
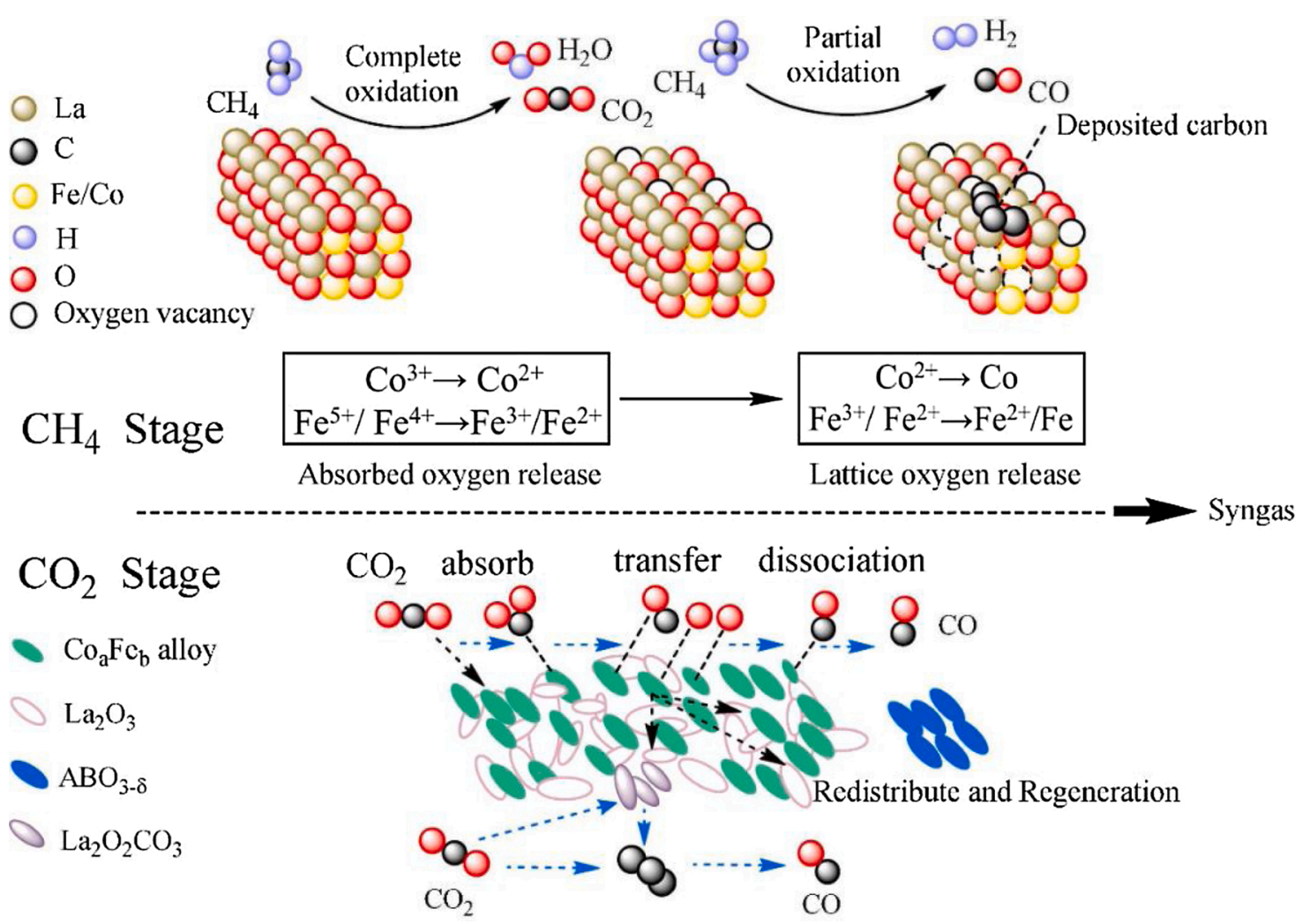

Fig. 10. Structural changes of $\mathrm{LaFe}_{\mathrm{x}} \mathrm{Co}_{1-\mathrm{x}} \mathrm{O}_{3}$ during coupling of $\mathrm{CH}_{4}$ partial oxidation and $\mathrm{CO}_{2}$ splitting for syngas. (Reaction conditions: $3 \mathrm{~g}$ of catalyst, $800{ }^{\circ} \mathrm{C}$, and 1 bar). Reproduced with permission from [60]. Copyright (2020) Elsevier. 
strong metal-support interaction with HAP support which largely stabilized the Ni single atoms towards agglomeration. These two factors were responsible for the great $100 \mathrm{~h}$ of time-on-stream DRM performance with negligible carbon deposit. Similar findings of single-atom Ni for DRM were also reported by Tang et al. [34] which exhibited a higher turnover rate of syngas yield and lower apparent activation barrier, most importantly, the atomic size of $\mathrm{Ni}$ only allowed first formed $\mathrm{H}$ atoms $\left(\mathrm{H}^{*}\right)$ through $\mathrm{CH}_{4}$ activation, hence no formation of carbon solid was found. Furthermore, the authors also provided an important mechanistic aspect on the synergistic effects of the two set of single- atom sites. Ni single-atom sites promote $\mathrm{CH}_{4}$ activation, while $\mathrm{Ru}$ single-atom sites enhance $\mathrm{CO}_{2}$ activation. The $\mathrm{H}^{*}$ atoms generated at Ni single-atom sites were then combine together to form $\mathrm{H}_{2}$ on $\mathrm{Ni}$ single-atom sites.

As a partial conclusion, solid carbon formed by methane decomposition and Boudouard reactions causes catalyst deactivation in TRM. However, under such oxidative conditions, solid carbon could be partially or completely gasified to regenerate the catalyst's active surface. Downsizing the active phase to singly dispersed atoms coupling with some modifications of the surface properties such as OCS, acidobasic character, MSI, by using appropriate supports and promoters could overcome the carbon solid deposition issues.

\subsection{Thermal degradation}

\subsubsection{Active phase sintering}

Sintering of heterogeneous catalysts is one of the main factors resulting in deactivation of catalyst induced by loss of catalytic surface area due to nucleation of small particles forming larger ones. In general, the metal particle growth is a result of size-dependent mobility of crystallites on support and their surface energy reduction which kinetically favors at high temperature. It could be primarily categorized into three mechanisms: (i) Ostwald ripening (atom migration), where metal atoms released from one crystallite migrate over the support and are captured by another crystallite; and (ii) vapor transport between particles at high temperatures. In fact, sintering is considerably a complex process and largely influenced by parameters including temperature, sintering time, chemical environment, catalyst structure, catalyst composition, and support morphology [50]. Fig. 11 showed an example of the evolution of $\mathrm{Ni}$ particles of a $\mathrm{Ni} / \mathrm{Al}_{2} \mathrm{O}_{3}$ after $\mathrm{CO}$ methanation reaction at $500{ }^{\circ} \mathrm{C}$ [68]. Accordingly, the average particle size increased from $50 \mathrm{~nm}$ for the fresh catalyst to $70 \mathrm{~nm}$ for the used catalyst. The authors explained that the sintering in this case was considerably owing to the agglomeration and migration of $\mathrm{Ni}$ nanoparticles.

In TRM conditions, steam could accelerate sintering by producing portable surface hydroxyl groups that are consequently vaporized at higher temperatures. This could be rationally due to the $\mathrm{Ni}_{2}-\mathrm{OH}$ species formation at $\mathrm{Ni}$ particles surface promoting the sintering process through particle migration. Such speculation has been proven by Sehested and the co-workers in their study of nickel sintering in steam reforming under various operating conditions $\left(\mathrm{H}_{2} \mathrm{O}: \mathrm{H}_{2}=0.2-10\right.$, $\mathrm{T}=483-682^{\circ} \mathrm{C}, \mathrm{P}=1-40$ bars) [15]. In the simultaneous presence of $\mathrm{H}_{2}$ and $\mathrm{H}_{2} \mathrm{O}$, the formation energy of $\mathrm{Ni}_{2}-\mathrm{OH}$ dimers was reportedly much lower than that of $\mathrm{Ni}$ adatoms based on their experimental results and density functional theory (DFT) calculations. In particular, as temperature grew, the activation energy and the corresponding sintering rate were evidently increased, accredited to predominant sintering process through Ostwald ripening.

As the active phase sintering is highly depending on catalyst composition, structure and support morphology, the relationship between the parameters including particle size, surface area and metalsupport interactions has been studied for developing an appropriate catalyst system in order to address the sintering problem. Generally, a catalyst with good dispersion of small metal particles on high-surfacearea support undoubtedly governing the catalytic performance but meanwhile, it has also a higher tendency for metal sintering due to particle migration [50]. According to the literature [69], the degree of interaction between active metal particles and support always plays an important role in the catalytic activity and stability, particular to the catalyst deactivation induced by sintering and at high temperature. A stronger metal-support interaction of a catalyst system can largely retain the metallic phase of hosting metal in association with metal particle size and subsequently suppresses the side reactions such as combustion and coke deposition in order to govern the high purity of syngas yield via TRM. To restrain the mobility of small metal particles at elevated temperature, support with high surface area and great anchor effect towards loaded metal particles has been developed such as SBA-15. In the investigation of metal-support interaction among Ni-based catalysts for TRM in respect of catalytic activity and stability, Kumar et al. [51] described that the micropore channels of SBA-15 not only created stronger interaction with $\mathrm{NiO}$ species benefiting catalytic activity but also resulted in a great $\mathrm{Ni}$ confinement from preventing sintering. In their evaluation of $10 \mathrm{~h}$ experimental TRM reaction runs over various Ni-loaded catalysts (Reaction conditions: $800{ }^{\circ} \mathrm{C}$, GHSV $=17,220 \mathrm{~mL}$ $\mathrm{h}^{-1} \mathrm{~g}^{-1}$, molar ratio of $\mathrm{CH}_{4}: \mathrm{CO}_{2}: \mathrm{H}_{2} \mathrm{O}: \mathrm{O}_{2}: \mathrm{N}_{2}=1: 0.23: 0.46: 0.07: 0.28$ ), $\mathrm{Ni} / \mathrm{SBA}-15$ exhibited an excellent catalytic stability with insignificant reduction in conversion rates. From the XRD patterns of used Ni/SBA-15 catalysts after long-term TRM runs, no considerable rise in crystallite size of Ni were discerned compared to their corresponding counterparts, attributed to the strong confinement effect of SBA-15 supported catalysts.

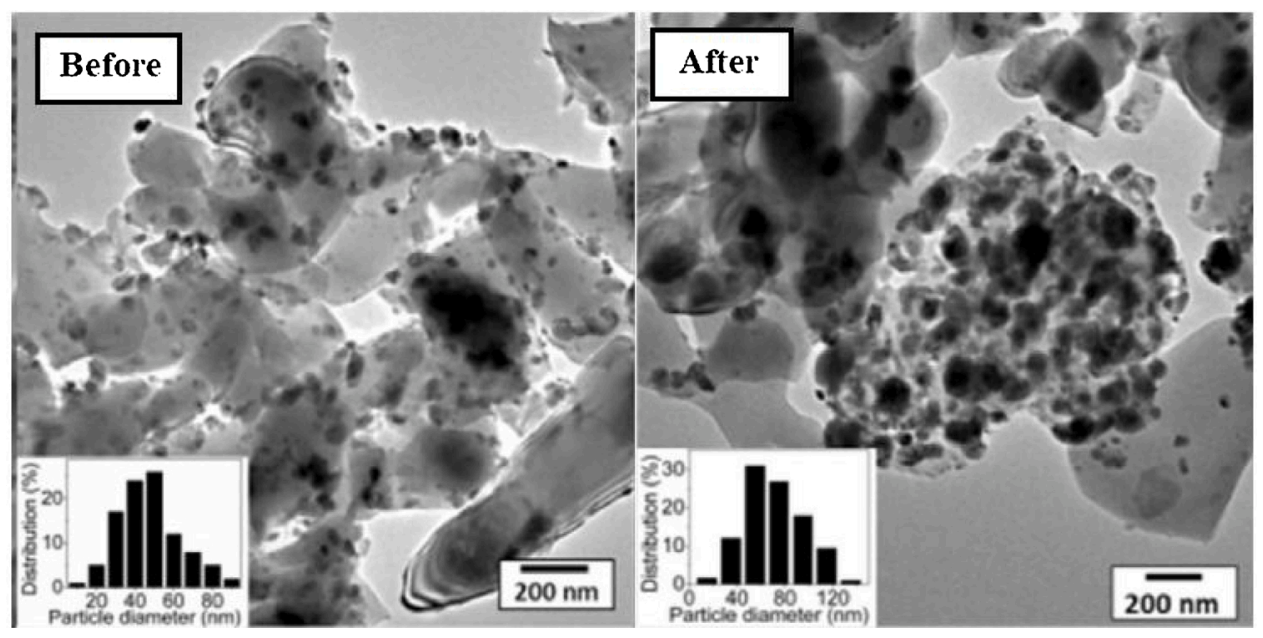

Fig. 11. TEM images of a $\mathrm{Ni} / \mathrm{Al}_{2} \mathrm{O}_{3}$ catalyst before and after $\mathrm{CO}$ methanation at $500{ }^{\circ} \mathrm{C}$. Other conditions: $0.2 \mathrm{~g}$ catalyst, molar ratio of $\mathrm{H}_{2}: \mathrm{CO}: \mathrm{N}_{2}=3: 1: 1$, inlet gas flowrate $=100 \mathrm{~mL} \mathrm{~min}^{-1}$ ). Adapted with permission from [68], Copyright 2018 Elsevier. 
Singha et al. [44] synthesized nanocrystalline $\mathrm{Ni}-\mathrm{ZrO}_{2}$ catalysts with various average Ni particle sizes (between $10-40 \mathrm{~nm}$ ) for longevity test of TRM (Reaction conditions: $\mathrm{T}=500-800{ }^{\circ} \mathrm{C}$, GHSV $=20000-400000 \mathrm{~mL} \quad \mathrm{~h}^{-1} \quad \mathrm{~g}^{-1}, \quad \mathrm{O}_{2}: \mathrm{CO}_{2}: \mathrm{H}_{2} \mathrm{O}: \mathrm{CH}_{4}$ : $\mathrm{He}=1: 1: 2.1: 5: 18)$ and reported that the smaller size of Ni particles enhanced metal-support interaction due to high metal dispersion on catalyst surface, which led to a superior $100 \mathrm{~h}$-on-stream TRM run $\left(\mathrm{CH}_{4}\right.$ conversion $=95 \%$ and $\mathrm{H}_{2} / \mathrm{CO}$ ratio $\approx 2$ ).

By controlling the Ni size at atomic level, Zhang et al. [66], who investigated the mechanism of DRM, found the effect of electron transfer between $\mathrm{Ni}_{2}$ (cluster containing $2 \mathrm{Ni}$ atoms) and the support of boron-vacancy-containing h-BN sheet. This effect results in a strong MSI, which in turn, favors strong resistance to sintering and to carbon deposition. In addition, low temperature operation of reforming process provided by application of SAC $[33,34]$ is also a good solution for sintering issue, as discussed in the Section 3.1. Operating temperature.

\subsubsection{Support sintering}

Apart from phase sintering, support sintering is also one of main factors accounting for catalyst deactivation. In fact, supports sintering can be resulted from one or more from the following processes, namely: solid-state diffusion, surface diffusion, condensation/evaporation of volatile atoms or molecules, phase transformation and grain boundary diffusion [50]. For instance, $\mathrm{Al}_{2} \mathrm{O}_{3}$ is widely used as a support in catalytic heterogeneous reactions but it encounters phase transformations, since $\mathrm{Al}_{2} \mathrm{O}_{3}$ owns a rich phase behavior as a function of preparation and temperature. In fact, $\mathrm{Al}_{2} \mathrm{O}_{3}$ can exist as $\gamma$-alumina at $300-450{ }^{\circ} \mathrm{C}$, $\delta$-alumina at around $850^{\circ} \mathrm{C}, \theta$-alumina at about $1000{ }^{\circ} \mathrm{C}$, and $\alpha$-alumina at around $1125{ }^{\circ} \mathrm{C}$, with respectively cubic defective spinel, orthorhombic, deformed monoclinic spinel, and hexagonal close pack as crystalline structure [50]. According to Argyle and Bartholomew [50], a drastic drop in surface area of alumina was reported during the phase transition from $\theta$-alumina to $\alpha$-alumina, ascribed to the dense hexagonal close pack phase formation and the collapse of the micro-structure with increasing temperature.

Lee et al. prepared various supported $\mathrm{Ni}$ catalysts and evaluated their catalytic performance for the long-term TRM process (reaction conditions: molar ratio of $\mathrm{CH}_{4}: \mathrm{CO}_{2}: \mathrm{N}_{2}=1: 1: 1$, molar ratio of $\mathrm{H}_{2} \mathrm{O}+\mathrm{O}_{2} / \mathrm{CO}_{2}$ $=2$, GHSV $\left.=72000 \mathrm{~mL} \mathrm{~h}^{-1} \mathrm{~g}^{-1}, \mathrm{~T}=800{ }^{\circ} \mathrm{C}, \mathrm{P}=1 \mathrm{~atm}\right)$. [70]. The higher degree of catalyst deactivation $(64.9 \%)$ for $\mathrm{Ni} / \gamma-\mathrm{Al}_{2} \mathrm{O}_{3}$ was reported through $80 \mathrm{~h}$-on-stream of reaction, accredited to the phase transformation of alumina making the catalyst inactive at high temperature. A similar observation was described by Pant and the co-workers in their evaluation of Ni-based catalysts prepared at various supports and calcination temperatures for TRM but the discussion was controversial with the former reports [51,70]. For the $\mathrm{Al}_{2} \mathrm{O}_{3}$ support, they observed that an increase in calcination temperature led to a higher extent of $\mathrm{NiAl}_{2} \mathrm{O}_{4}$ crystallinity, which was responsible for a greater TRM activity due to the reduction of $\mathrm{NiAl}_{2} \mathrm{O}_{4}$ produced monodispersed $\mathrm{Ni}$ atoms that highly related to $\mathrm{Al}_{2} \mathrm{O}_{3}$ phase, which subsequently activated reaction intermediate species enhancing the rate of reforming reaction. Particularly, the $\mathrm{CH}_{4}$ conversion rate was enhanced about $18.1 \%$ as the calcination temperature for $\mathrm{Ni} / \mathrm{Al}_{2} \mathrm{O}_{3}$ catalysts increased from 400 to $950^{\circ} \mathrm{C}$. In the study of additive effect (i.e., Ce, Co, and $\mathrm{K}$ ) on the catalytic performance of NiMo-C/ $\gamma-\mathrm{Al}_{2} \mathrm{O}_{3}$ catalyst in TRM, Zou et al. found that the phase transformation of the alumina support could be induced by type of additives, which enormously counteracted the positive effect of additives [71]. In comparison to other additive-doped catalysts, the K-doped NiMo-C $/ \gamma-\mathrm{Al}_{2} \mathrm{O}_{3}$ only exhibited $17.4 \%$ of $\mathrm{CH}_{4}$ conversion with an insignificant syngas yield $(<10 \%)$ at $850{ }^{\circ} \mathrm{C}$. They assigned this behavior to the phase transformation from active $\gamma$-alumina into inactive $\theta$-alumina in the presence of $\mathrm{K}$, resulting in large aggregates of unevenly dispersed particles and as a result, $\mathrm{K}$-doped NiMo-C $/ \gamma-\mathrm{Al}_{2} \mathrm{O}_{3}$ possessed the poorest physical properties. However, Zou et al. [71] did not provide the detailed discussion regarding the correlation between $\mathrm{K}$ additive and the phase transformation of alumina at molecular level.
Apart from the alumina, the adverse effect of phase transformation for $\mathrm{TiO}_{2}$ in reforming reactions was also extensively reported and studied by other researchers. By characterizing both fresh and spent $\mathrm{Ni}$ / $\mathrm{TiO}_{2}$ and $\mathrm{Ni} / \mathrm{Mg}_{0.25} \mathrm{Ti}_{0.75} \mathrm{O}$ catalysts after TRM reaction (reaction conditions: $1 \mathrm{~g}$ of catalyst, $850{ }^{\circ} \mathrm{C}, 1 \mathrm{bar}$, molar ratio of $\mathrm{CH}_{4}: \mathrm{CO}_{2}: \mathrm{H}_{2} \mathrm{O}: \mathrm{O}_{2}$ $=1: 0.48: 0.54: 0.1$, inlet $\mathrm{CH}_{4}$ flowrate $=250 \mathrm{~mL} \mathrm{~min}^{-1}$ ), Jiang et al. corroborated the formation of rutile- $\mathrm{TiO}_{2}$ (after reaction) from its anatase form (before reaction) [72]. Such phenomena led to severe metal sintering and formation of carbonaceous species, as proven in the TG analysis and SEM micrographs, due to a drastic decrease in specific surface area of support and as a result, poorer catalytic activity. In the investigation of calcination effect of $\mathrm{TiO}_{2}$ supported catalysts on their catalytic behavior, a phase evolution of anatase- $\mathrm{TiO}_{2}$ into rutile- $\mathrm{TiO}_{2}$ was evidently confirmed for $\mathrm{Ni} / \mathrm{TiO}_{2}$ case with rising calcination temperature. This evolution contributed to the reduction in catalytic activity of $\mathrm{Ni} / \mathrm{TiO}_{2}$ and a higher degree of catalyst deactivation during TRM owing to the dramatic decline in specific surface area [50,51]. In comparison with $\mathrm{Ni} / \mathrm{TiO}_{2}$ calcined at $400{ }^{\circ} \mathrm{C}$ (anatase- $\mathrm{TiO}_{2}$ ), the $\mathrm{Ni} / \mathrm{TiO}_{2}$ calcined at $850{ }^{\circ} \mathrm{C}$ (rutile- $\mathrm{TiO}_{2}$ ) exhibited a considerably inferior rate of $\mathrm{CH}_{4}$ conversion which was around $24.1 \%$ lower, dropped from $5.81 \times 10^{-2}$ to $4.43 \times 10^{-2} \mathrm{mmol} \mathrm{g}_{\text {cat }}^{-1} \mathrm{~s}^{-1}$. To correlate the $\mathrm{TiO}_{2}$ phase composition and catalytic performance in TRM, Mateos-Pedrero et al. prepared two types of $\mathrm{TiO}_{2}$ with different rutile/anatase compositions as support for $\mathrm{Rh} / \mathrm{TiO}_{2}$ catalysts [73]. They found that the anatase-rich $\mathrm{TiO}_{2}$ supported $\mathrm{Rh}$ catalyst exhibited greater $\mathrm{CH}_{4}$ conversion (increased by around $30 \%$ ) and selectivity of $\mathrm{H}_{2}$ (increased by around $15 \%$ ) and CO (increased by around $20 \%$ ) in comparison with that of rutile-rich counterpart. This could be accredited to the higher capability of hosting active metal over anatase-rich $\mathrm{TiO}_{2}$ support, which leads to an enhancement in the degree of reducibility of Rh particles and well dispersion as well as lower tendency of metal re-oxidation.

Such loss in specific surface area and catalytic reactivity along with a degradation in mechanical stability due to support sintering at hightemperature reaction were also found in pristine zirconia support as reported by Lino et al. [74] in their study of various $\mathrm{X}_{-} \mathrm{ZrO}_{2}$ addition on $\mathrm{Ni} / \mathrm{MgAl}_{2} \mathrm{O}_{4}$ for TRM (reaction conditions: $750^{\circ} \mathrm{C}, 1$ bar, molar ratio of $\mathrm{CH}_{4}: \mathrm{CO}_{2}: \mathrm{H}_{2} \mathrm{O}: \mathrm{O}_{2}: \mathrm{N}_{2}=3: 1: 1.4: 0.5: 2$, inlet $\mathrm{CH}_{4}$ flowrate $=51.5 \mathrm{~N} \mathrm{~mL}$ $\mathrm{min}^{-1}$, TOS $=6 \mathrm{~h}$ ). This drawback could be counteracted by introducing promoter on the catalyst surface, which not only facilitated the dispersion hosting active metal providing more active sites for surface reaction but also effectively suppressing carbon deposition resulted from strengthened basicity strength.

Apart from phase transformation, material vaporization would also cause a damage towards support structure and resulted in sintering such as silica. At a steam-enriched environment with high temperature, like in TRM, silica support reportedly underwent silica vaporization [31]. The post-reaction characterizations including SEM and FTIR confirmed the structural integrity of $\mathrm{Ni@SiO}{ }_{2}$ after TRM reaction as the core-shelled $\mathrm{Ni}$ coating and the characteristic bands attributed to $\mathrm{Ni} @ \mathrm{SiO}_{2}$ were largely preserved. TRM reaction requires high reaction temperatures $\left(700-900{ }^{\circ} \mathrm{C}\right.$ ) which can cause the thermal sintering of both the active phase and the support. A thermal pretreatment of the support before the catalyst preparation can be useful to stabilize catalyst structure, as previously demonstrated by Rêgo de Vasconcelos et al. for DRM process [75].

\subsection{Solid-solid or vapor-solid reactions}

\subsubsection{Active phase losses by dissolution with support}

As discussed in the previous section, interaction between hosting metal and support (i.e., $\mathrm{Al}_{2} \mathrm{O}_{3}, \mathrm{MgO}, \mathrm{TiO}_{2}$ ) can form inactive solid solutions or composite materials during catalyst preparation and utilization which leads to loss of active phase for TRM reaction [6,51,72]. As the first research group investigated TRM process, Song and Pan found that $\mathrm{NiO} / \mathrm{MgO}$ solid solution was easily to form on $\mathrm{Ni} / \mathrm{MgO}$ catalyst, regardless of the calcination temperature [6]. They assigned this 
observation to the similar ironic radii of both $\mathrm{Mg}$ and $\mathrm{Ni}$ cations and as a result, they are easily to form a significant solid solution. In the presence of $\mathrm{NiO} / \mathrm{MgO}$ solid solution, the degree of reducibility for $\mathrm{Ni} / \mathrm{MgO}$ catalyst was substantially lower due to the increased energy barrier of $\mathrm{NiO}$ reduction to metallic $\mathrm{Ni}$ particles. As a result, the low $\mathrm{Ni}$ dispersion associated with the formation of $\mathrm{NiO} / \mathrm{MgO}$ solid solution could adversely influence the TRM activity. Such observation is also supported by findings of Kumar et al. [51] in their TRM assessment over $\mathrm{Ni} / \mathrm{TiO}_{2}$ catalysts that calcined at different temperature. The formation of $\mathrm{NiTiO}_{3}$ was significantly noticed at the elevated calcination temperature of $\mathrm{Ni} / \mathrm{TiO}_{2}$ preparation. They found that the $\mathrm{NiO}$ particles required higher temperature to complete the reduction process in the existence of $\mathrm{NiTiO}_{3}$ and as a result, a relatively lower Ni reducibility and poorer Ni dispersion were obtained. The subsequent adverse effect was reflected on its catalytic performance in terms of conversion rate of methane due to loss of $\mathrm{Ni}$ active phase. Interestingly, Jiang et al. discovered that the formation of $\mathrm{NiO} / \mathrm{MgO}$ solid solution could be enormously obstructed by introducing $\mathrm{Ti}$ into the $\mathrm{NiO}-\mathrm{MgO}$ system and subsequently improved the reducibility [72]. An appropriate quantity of Ti addition into $\mathrm{NiO} / \mathrm{MgO}$ catalyst reportedly contributed to create a moderate metal-support interaction, which was responsible for improvement in both degrees of reducibility and catalytic stability.

\subsubsection{Re-oxidation of the active phase}

The number of active sites for activated metallic phase is always the key element determining the corresponding catalysis activity in catalytic heterogeneous reactions. At a highly oxidative environment such as TRM, loss of active sites due to re-oxidation forming inactive metal oxides could occur and causing undesired deactivation although the excessive oxidizing agents (i.e., $\mathrm{O}_{2}, \mathrm{CO}_{2}$ and $\mathrm{H}_{2} \mathrm{O}$ ) effectively promote carbon elimination and catalytic activity [48]. In order to fundamentally understand the re-oxidation process of metallic phase to metal oxides, a study of thermal distribution along the catalyst bed $\left(\mathrm{Ni} / \gamma-\mathrm{Al}_{2} \mathrm{O}_{3}\right)$ for TRM was conducted by Jiang et al. [48] (reaction conditions: $1 \mathrm{~g}$ of catalyst, $950{ }^{\circ} \mathrm{C}$, atmospheric pressure, molar ratio of $\mathrm{CH}_{4}: \mathrm{CO}_{2}: \mathrm{H}_{2} \mathrm{O}$ : $\mathrm{O}_{2}=50: 12.5: 12.5: 25 \mathrm{~mol} \%$, WHSV $=10,000 \mathrm{~h}^{-1}$, TOS $=10 \mathrm{~h}$ ). Based on the disparity of temperature distribution along the reactor and consideration of multiple reactions involved, they categorized the whole reactor length into three zones, namely, oxygen adequate zone (where complete oxidation of methane was predominant), oxygen inadequate zone (where methane reforming processes were dominant) and oxygen absent zone (where oxygen was absent) as shown in Fig. 12. Throughout the transition of zones, they reported the corresponding transformation of $\mathrm{Ni}$ oxidation state, where $\mathrm{Ni}^{2+}$ in oxygen adequate zone could evolve to a mixture of $\mathrm{Ni}^{2+}$ and $\mathrm{Ni}^{\circ}$ in oxygen inadequate zone, and eventually to $\mathrm{Ni}^{\circ}$ in oxygen absent zone. This indicates the concentration level of oxygen was the decisive factor to the re-oxidation degree.

In order to overcome the abovementioned issue, Jiang al. [76] synthesized the Pt modified $\mathrm{Ni} / \mathrm{MgO}$ catalysts and examined their resistibility towards re-oxidation for TRM reaction. From their findings, the Pt addition was able to preserve the metallic $\mathrm{Ni}^{\circ}$ phase due to the formation of Ni-Pt alloy on catalyst surface and hence, resist the re-oxidation. In the presence of Ni-Pt alloy, they also surprisingly found that the TRM reaction zone was divided into two zones, namely, auto-thermal reforming zone and oxygen absent zone, which was different from that over $\mathrm{Ni} / \mathrm{Al}_{2} \mathrm{O}_{3}$. In both zones, the $\mathrm{Ni}-\mathrm{Pt}$ alloy was actively activated in metallic form and none of the corresponding metal oxides were observed during TRM. Such a beneficial effect of second metal addition on inhibition of re-oxidation is also justified by Jiang et al. [72] in their research work about $\mathrm{Ni} / \mathrm{Mg}_{\mathrm{x}} \mathrm{Ti}_{1-\mathrm{x}} \mathrm{O}$ catalyst for catalytic stability of TRM. They found that re-oxidation of $\mathrm{Ni}^{\circ}$ is the main reason accounting for decrease in both $\mathrm{CH}_{4}$ conversion (from $93 \%$ to $83 \%$ ) and $\mathrm{CO}_{2}$ conversion (from $82 \%$ to $72 \%$ ) in 6 h-on-stream TRM reaction over $\mathrm{Ni} / \mathrm{MgO}$ catalyst. However, with the addition of $\mathrm{TiO}_{2}$, the $\mathrm{Ni} / \mathrm{Mg}_{\mathrm{x}} \mathrm{Ti}_{1-\mathrm{x}} \mathrm{O}$ catalyst exhibited a consistent $\mathrm{CH}_{4}$ conversion and $\mathrm{CO}_{2}$ conversion around $98 \%$ and $80 \%$, respectively which lasted for 50 h-on-stream TRM activity. Similar observation for $\mathrm{Ni} / \mathrm{MgO}$ catalyst is reported by Song et al. [6].

Kumar et al. [51,52] observed the re-oxidation with $\mathrm{Ni} / \mathrm{MgO}$, $\mathrm{Ni} / \mathrm{TiO}_{2}, \mathrm{Ni} / \mathrm{SBA}-15, \mathrm{Ni} / \mathrm{Al}_{2} \mathrm{O}_{3}$ catalysts during TRM. Solov'ev et al. [45] reported that $\mathrm{NiO} / \mathrm{Al}_{2} \mathrm{O}_{3}$ catalyst achieved almost $100 \%$ of $\mathrm{CH}_{4}$ conversion during DRM and SRM but it only exhibited $15 \%$ of $\mathrm{CH}_{4}$ conversion during TRM rationally due to the re-oxidation of Ni. Pino et al. [40] also observed the catalytic deactivation of $\mathrm{Ce}_{0.25} \mathrm{La}_{0.50} \mathrm{Ni}_{0.25} \mathrm{O}_{2-\delta}$ catalyst resulted from the re-oxidation of $\mathrm{Ni}$. The authors assigned this behaviour to the excessive oxygen that not involved in the interactions of vacancies presenting in catalyst surface, which oxidizes both the carbon deposits and the dispersed Ni particles on catalysts surface which owns a weak metal-support interaction. Kim et al. [77] inspected the effect of various $\left(\mathrm{CO}_{2}+\mathrm{H}_{2} \mathrm{O}+\mathrm{O}_{2}\right)$ to methane $(\mathrm{O} / \mathrm{M})$ feed compositions on catalytic performance of $\mathrm{NiCe} / \mathrm{SiO}_{2}$ multi-yolk-shell nanotube catalyst in TRM. They found that the catalyst exhibited an outstanding carbon resilience under reducing conditions $(\mathrm{O} / \mathrm{M} \leq 1)$ whilst re-oxidation of active metallic $\mathrm{Ni}^{\circ}$ to $\mathrm{Ni}^{2+}$ tends to occur under oxidizing conditions $(\mathrm{O} / \mathrm{M}>1)$. In addition, employment of that $\mathrm{ZrO}_{2}$ and mixed oxides of $\mathrm{CeO}_{2}-\mathrm{ZrO}_{2}$ as the support reportedly could overcome the re-oxidation of metallic $\mathrm{Ni}$ form, accredited to the oxophilic and redox property [52]. A strong interaction between
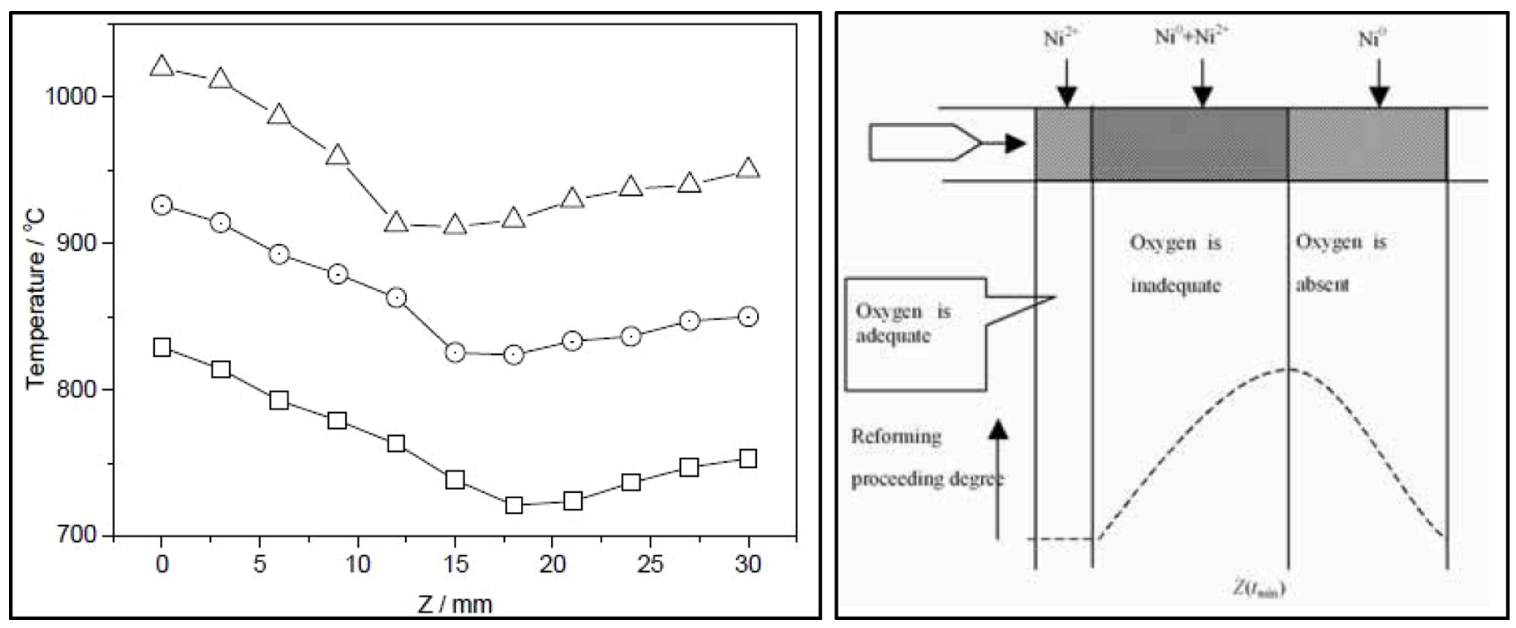

Fig. 12. Temperature profile of the catalyst bed (left) and scheme of the three reaction zones in $\mathrm{TRM}$ over $\mathrm{Ni} / \mathrm{Al}_{2} \mathrm{O}_{3}$ (right). (Reaction conditions: $1 \mathrm{~g}$ of catalyst, $950{ }^{\circ} \mathrm{C}, 1$ bar, molar ratio of $\mathrm{CH}_{4}: \mathrm{CO}_{2}: \mathrm{H}_{2} \mathrm{O}: \mathrm{O}_{2}=50: 12.5: 12.5: 25 \mathrm{~mol} \%$, WHSV $=10,000 \mathrm{~h}^{-1}$, TOS $=10 \mathrm{~h}$ ). Adaptation with permission from [48]. Copyright 2007 Elsevier. 
primary metal and secondary metal is also beneficial to the suppression on the re-oxidation of metal in TRM. Kumar et al. [78] synthesized Zn promoted $\mathrm{Ni} / \mathrm{Mg}$-Al mixed oxide for of TRM, the catalyst showed a remarkable TRM activity with $20.12 \times 10^{-2} \mathrm{mmol} \mathrm{g}_{\text {cat }}^{-1} \mathrm{~s}^{-1}$ of $\mathrm{CH}_{4}$ conversion rate, $5.56 \times 10^{-2} \mathrm{mmol} \mathrm{g}_{\text {cat }}^{-1} \mathrm{~s}^{-1}$ of $\mathrm{CO}_{2}$ conversion rate and $9.14 \times 10^{-2} \mathrm{mmol} \mathrm{g}_{\text {cat }}^{-1} \mathrm{~s}^{-1}$ of $\mathrm{H}_{2} \mathrm{O}$ conversion rate. This was attributed to the excellent electronic and geometric effects of $\mathrm{Zn}$, which facilitated electron transfer from $\mathrm{Zn}$ to $\mathrm{Ni}$ creating a strong interaction to promote the $\mathrm{CH}_{4}$ activation. In addition, the geometric isolation of active Ni sites owing to the existence of $\mathrm{Zn}$ caused the hindrance of coke formation, thus prolonged the catalyst lifespan.

High temperatures and oxidizing atmosphere of TRM can provoke chemical modification of the catalyst during the reaction, including the re-oxidation and the dissolution of the active phase with the support. If the oxidized metal can be reactivated by hydrogen reduction, the dissolution of the active phase generally causes the irreversible catalyst deactivation. This can be limited by using an appropriate additive agent as demonstrated by Jiang et al. [72].

\subsection{Catalyst poisoning}

In methane reforming processes, catalyst poisoning due to the strong chemisorption of impurities on active sites of catalyst is unpreventable as the methane source (i.e., biogas and natural gas) typically contains a minor amount of $\mathrm{H}_{2} \mathrm{~S}$ [79]. According to literature [50,80], the adsorption of $\mathrm{H}_{2} \mathrm{~S}$ molecules on metal surface would lead to surface coverage and subsequently dissociates through the formation of a bulk sulfide phase. The formation of sulfur-containing compounds on the metal surface inhibits the accessibility of reactants to the active sites of metal particles and thus, suppression on the surface reaction. In the investigation of catalyst poisoning caused by gas impurities (i.e., $\mathrm{H}_{2} \mathrm{~S}$ and $\mathrm{NH}_{3}$ ) for biogas reforming process over $\mathrm{Ni}-\mathrm{Rh} / \mathrm{MgAl}_{2} \mathrm{O}_{4}$ catalyst (reaction conditions: $20 \mathrm{mg}$ of catalyst, inlet gas flowrate $=100 \mathrm{~mL}$ $\min ^{-1}, 9.5 \mathrm{~mL} \min ^{-1}$ of $\mathrm{N}_{2}, 7.5 \mathrm{ppm}$ of $\mathrm{H}_{2} \mathrm{~S}$, molar ratio of $\mathrm{O}_{2} / \mathrm{CH}_{4}=0.375$, molar ratio of $\mathrm{O} / \mathrm{C}=3$, balanced with Ar), Yin et al. [81] reported that the rapid catalyst deactivation due to the blockage of reforming and oxidation sites was observed in the presence of gas impurities. In addition, the removal of gas impurities, particularly $\mathrm{H}_{2} \mathrm{~S}$ gas from the reactant feeds, did not result in the restoration of reaction activity. This speculation is supplemented by their EDS analyses for spent catalysts after tested with various amounts of $\mathrm{H}_{2} \mathrm{~S}$ gas in reactant feeds, which revealed that the increase in sulfur deposition on $\mathrm{Ni}$ particles was directly related to the growing $\mathrm{H}_{2} \mathrm{~S}$ concentration.

Kantserova et al. [80] scrutinised the catalytic activity of $\mathrm{Ni}$-containing composites (i.e., $\mathrm{Ni}-\mathrm{Cu}-\mathrm{CeO}_{2}, \mathrm{Pd}-\mathrm{Ni}$, and $\mathrm{Pt}-\mathrm{Ni}$ ) and their resistance to sulfur poisoning for TRM (reaction conditions: $800{ }^{\circ} \mathrm{C}$, 1 bar, molar ratio of $\mathrm{CH}_{4}: \mathrm{CO}_{2}: \mathrm{H}_{2} \mathrm{O}: \mathrm{O}_{2}: \mathrm{Ar}=4: 6: 5: 0.5: 84.5$, inlet gas flowrate $=90 \mathrm{~mL} \mathrm{~min}^{-1}, 3500 \mathrm{ppm} \mathrm{H}_{2} \mathrm{~S}$ ). The Ni-Cu-CeO${ }_{2}$ catalyst performed a low resistance to sulfur poisoning as it was promptly lost up to $42 \%$ of $\mathrm{CH}_{4}$ conversion after $70 \mathrm{~min}$ of reaction run. Conversely, Pd-Ni and $\mathrm{Pt}-\mathrm{Ni}$ catalysts demonstrated the greatest resistance to the poisoning effect of $\mathrm{H}_{2} \mathrm{~S}$, in particular the $\mathrm{CH}_{4}$ conversion only dropped by $15 \%$ after $2 \mathrm{~h}$ of reaction duration although the clogging of active sites by surface sulfur-containing compounds was evidenced. The authors concluded that the catalyst resistance to $\mathrm{H}_{2} \mathrm{~S}$ poisoning increased as the corrosion resistance order of the metal active components for the composites in the air where saturated with water vapor containing a trace of hydrogen sulfide: $\mathrm{Cu}, \mathrm{Ni}<\mathrm{Pt}<\mathrm{Pd}$. Regarding the regeneration, the authors suggested that a double treatment $\left(\mathrm{H}_{2} \mathrm{O}\right.$ oxidation over $10 \mathrm{~h}$, followed by $\mathrm{H}_{2}$ reduction at $800{ }^{\circ} \mathrm{C}$ ) and increasing time for the regeneration could be the promising solution for restoring the initial activity of the Pd-Ni catalyst [80].

Since the study of $\mathrm{H}_{2} \mathrm{~S}$ concentration on TRM is still vague, we can refer to the relevant works on DRM and SRM as the TRM involves these two reforming processes in the system. In order to assess the poisoning effect of $\mathrm{H}_{2} \mathrm{~S}$ concentration on catalysis activity, Chattanathan et al. conducted DRM as a function of temperature under various $\mathrm{H}_{2} \mathrm{~S}$ contents [82]. The work found that a minor amount of $\mathrm{H}_{2} \mathrm{~S}(0.5 \mathrm{~mol} \%)$ introduction could lead to about $20 \%$ decline in both $\mathrm{CH}_{4}$ and $\mathrm{CO}_{2}$ conversions compared to their initial catalytic activity (65\% of $\mathrm{CH}_{4}$ conversion and $85 \%$ of $\mathrm{CO}_{2}$ conversion) in the absence of $\mathrm{H}_{2} \mathrm{~S}$. Additionally, they reported that there was no obvious difference in surface morphology between the fresh and used catalysts before the introduction of $\mathrm{H}_{2} \mathrm{~S}$. However, the agglomeration of sulfur crystals was clearly observed for the spent catalyst after $\mathrm{H}_{2} \mathrm{~S}$ introduction during reaction. An analogous finding was also stated by Appari et al. in their study about the regeneration and deactivation of $\mathrm{Ni}$ catalyst during biogas steam reforming at various temperature and $\mathrm{H}_{2} \mathrm{~S}$ concentration [83]. They reported that the deactivation rate was independent of temperature at high $\mathrm{H}_{2} \mathrm{~S}$ content (50 and $100 \mathrm{ppm}$ ), suggesting the catalyst deactivation was completely attributed to the sulfur deposition. Apart from that, the catalytic activity of sulfur deposited catalyst could be partially recovered up to $32 \%$ of $\mathrm{CH}_{4}$ conversion at high temperature by removing $\mathrm{H}_{2} \mathrm{~S}$ gas from the feedstock. Izquierdo et al. [83] studied the different regeneration methods, namely, self-regeneration and low-temperature oxidative regeneration for sulfur poisoned catalysts in TRM. Similar to other reported TRM works, all catalysts were rapidly deactivated in the presence of $\mathrm{H}_{2} \mathrm{~S}$ during TRM process. Results of regeneration processes showed that the restoration of catalytic activity for $\mathrm{Ni} / \mathrm{Ce}-\mathrm{Zr}-\mathrm{Al}_{2} \mathrm{O}_{3}$ and $\mathrm{Ni} / \mathrm{Ce}-\mathrm{Al}_{2} \mathrm{O}_{3}$ catalysts could be completely recovered, which was comparable to their initial activity before sulfur poisoning. However, a small amount of sulfur was still evidently identified on the surface of regenerated catalysts by the XPS measurement after regeneration processes.

\section{Conclusions and outlook}

In the quest for commercializing and implementing TRM in the industrial syngas production, it is essential to develop an excellent catalyst system in terms of catalytic performance and stability. In the TRM system, the highly endothermic nature of SRM and DRM resulting in high energy requirement can be compensated by the co-existing exothermic total or partial oxidation of methane. To date, theoretical and experimental studies reported in the literature reveal that the efficiency of TRM process strongly depends on the operating conditions. Accordingly, TRM reaction is favored by high temperature, but disfavored by high pressure and high GHSV. Feed composition determines the TRM performance as it strongly affects the individual SRM, DRM and POM reactions, and in turn, determines the compositions of syngas produced.

In comparison with other methane reforming processes, the encountered technical difficulties for implementing TRM reaction are more challenging as its catalyst deactivation is not only caused by carbonaceous deposition. Factually, in TRM reaction, catalyst deactivation due to coke deposition, thermal degradation, vapor-solid reactions and poisoning of gas impurities seems to be inevitable. As a result, studies in association with excellent resistance and regenerability to overcome abovementioned problems have been extensively conducted for catalyst development by utilizing various metals groups and supports. The employment of appropriate metals or supports possessing unique catalyst structure, and redox or basic characteristics contributes to avoid the deterioration of catalyst system mainly induced by sintering and the deposition of carbonaceous species or gas impurities. Specified groups of metals with great basicity strength can contribute to maintain a balance between formation and oxidation of carbonaceous species, hence resulting in an excellent and prolonged catalytic performance. Using appropriate catalyst synthesis approaches, different extents of metal-support interaction or surface configuration can be created for solving catalyst deactivation through enhanced resistance to metal sintering. The formation of oxygen vacancy sites is closely related to the capability of support releasing and storing oxygen atoms under reducing-oxidizing cycles. These defects act as active sites to dissociate the oxidizing agents and provide $\mathrm{O}$ species to carbon removal process. Nevertheless, bibliographic information regarding the TRM is still vague 
in research works. In order to efficiently design a carbon-resistant and sintering-resistant catalyst system, the study of advanced strategies for catalyst synthesis in association with physicochemical attributes (i.e., the dispersion of metal particles, and degree of metal-support interaction) is crucial. Additionally, studies about mechanism-derived kinetic modelling are important for catalyst and reactor design as well as process optimization. In this regard, the future works are expectedly tackled the issue of kinetic study and advanced strategies for catalyst synthesis approaches to further improve the catalytic stability and performance in TRM process for realizing its application in industrial realm.

\section{CRediT authorship contribution statement}

Doan Pham Minh: Conceptualization, Writing- Original draft preparation, Editing, Supervision, Reviewing, Validation, Funding acquisition. Xuan-Huynh Pham: Data curation, Writing- Original draft preparation. Tan Ji Siang: Data curation, Writing- Original draft preparation. Dai-Viet N. Vo: Writing- Reviewing.

\section{Declaration of Competing Interest}

The authors report no declarations of interest.

\section{Acknowledgments}

Part of this work was financially supported by ANR (France) via CARNOT M.I.N.E.S in the context of the project HyTrend.

\section{References}

[1] W. Cho, T. Song, A. Mitsos, J.T. McKinnon, G.H. Ko, J.E. Tolsma, D. Denholm, T. Park, Catal. Today 139 (2009) 261-267, https://doi.org/10.1016/j. cattod.2008.04.051.

[2] S. Jain, D. Newman, A. Nzihou, H. Dekker, P. Le Feuvre, H. Richter, F. Gobe, C. Morton, R. Thompson, Global Potential of Biogas, World Biogas Association, 2019.

[3] U. Izquierdo, V.L. Barrio, J. Requies, J.F. Cambra, M.B. Güemez, P.L. Arias, Int. J. Hydr. Ener. 38 (2013) 7623-7631, https://doi.org/10.1016/j ijhydene.2012.09.107.

[4] X. Zhao, B. Joseph, J. Kuhn, S. Ozcan, iScience 23 (2020), 101082, https://doi.org/ 10.1016/j.isci.2020.101082.

[5] C. Song, Chem. Innov. 31 (2001) 21-26.

[6] C. Song, W. Pan, Catal. Today 98 (2004) 463-484, https://doi.org/10.1016/j. cattod.2004.09.054.

[7] M. Halmanna, A. Steinfeld, Energy 31 (2006) 3171-3185, https://doi.org/ 10.1016/j.energy.2006.03.009.

[8] Z. Zhang, S.Y. Pan, H. Li, J. Cai, A.G. Olabi, E.J. Anthony, V. Manovic, Ren. Sust Ener. Rev. 125 (2020) 109799, https://doi.org/10.1016/j.rser.2020.109799.

[9] J.P. Lange, Catal. Today 64 (2001) 3-8, https://doi.org/10.1016/S0920-5861(00) 00503-4.

[10] R. Munirathinam, D. Pham Minh, A. Nzihou, Ind. Eng. Chem. Res. 57 (2018) 16137-16161, https://doi.org/10.1021/acs.iecr.8b03850.

[11] T.L. LeValley, A.R. Richard, M. Fan, Int. J. Hydr. Ener. 39 (2014) 16983-17000, https://doi.org/10.1016/j.ijhydene.2014.08.041.

[12] B. Rêgo de Vasconcelos, L. Zhao, P. Sharrock, A. Nzihou, D. Pham Minh, Appl. Surf. Sci. 390 (2016) 141-156, https://doi.org/10.1016/j.apsusc.2016.08.077.

[13] L.J.L. Maciel, A.E.M. de Souza, V.O. Cavalcanti-Filho, A. Knoechelmann, C.A.M. de Abreu, React. Kinet. Mech. Catal. 101 (2010) 407-416, https://doi.org/10.1007/ s11144-010-0232-9.

[14] C.H. Bartholomew, Appl. Catal. A Gen. 212 (2001) 17-60, https://doi.org/ 10.1016/S0926-860X(00)00843-7.

[15] J. Sehested, J.A.P. Gelten, I.N. Remediakis, H. Bengaard, J.K. Nørskov, J. Catal. 223 (2004) 432-443, https://doi.org/10.1016/j.jcat.2004.01.026.

[16] Y. Zhang, S. Zhang, J.L. Gossage, H.H. Lou, T.J. Benson, Ener. Fuels 28 (2014) 2717-2726, https://doi.org/10.1021/ef500084m.

[17] D. Pham Minh, T.J. Siang, D.V.N.Vo, T.S. Phan, A. Nzihou, D. Grouset, Hydrogen production from biogas reforming : an overview of steam reforming, dry reforming, dual reforming, and tri-reforming of methane, in: C. Azzaro-Pantel (Ed.), Hydrogen Supply Chain, Academic Press, Amsterdam, 2019, pp. 111-166, https://doi.org/ 10.1016/B978-0-12-811197-0.00004-X.

[18] D. Pham Minh, T.S. Phan, D. Grouset, A. Nzihou, J. Clean Ener. Technol. 6 (2018) 309-313, https://doi.org/10.18178/JOCET.2018.6.4.480.

[19] T.S. Phan, Élaboration, caractérisation et mise en œuvre d'un catalyseur dans le reformage du biogaz en vue de la production d'hydrogène vert, IMT Mines Albi, 2020 (Accessed March 25, 2021) PhD thesis, http://theses.fr/s164217.
[20] A.M. Borreguero, F. Dorado, M. Capuchino-Biezma, L. Sanchez-Silva, J.M. GarciaVargas, Int. J. Hydro. Ener. 45 (2020) 26623-26636, https://doi.org/10.1016/j. ijhydene.2020.07.013.

[21] J.R. Rostrup-Nielsen, Catalytic steam reforming, in: J.R. Anderson, M. Boudart (Eds.), Catalysis: Science and Technology, Springer-Verlag, 1984, p. 1.

[22] J.H. Bitter, K. Seshan, J.A. Lercher, J. Catal. 183 (1999) 336-343, https://doi.org/ 10.1006/jcat.1999.2402.

[23] J.H. Edwards, A.M. Maitra, Fuel Proc. Technol. 42 (1995) 269-289, https://doi. org/10.1016/0378-3820(94)00105-3.

[24] J.M. Garcia-Vargas, J.L. Valverde, J. Diez, F. Dorado, P. Sanchez, Int. J. Hydr. Ener. 40 (2015) 8677-8687, https://doi.org/10.1016/j.ijhydene.2015.05.032.

[25] J. Wei, E. Iglesia, J. Catal. 224 (2004) 370-383, https://doi.org/10.1016/j. jcat.2004.02.032.

[26] A. de la Osa, A. de Lucas, A. Romero, J. Valverde, P. Sanchez, Int. J. Hydr. Ener. 36 (2011) 9673-9684, https://doi.org/10.1016/j.ijhydene.2011.05.043.

[27] S. Chen, J. Zaffran, B. Yang, Appl. Catal. B: Env. 270 (2020), 118859, https://doi. org/10.1016/j.apcatb.2020.118859.

[28] A.T.F. Afolabi, C.Z. Li, P.N. Kechagiopoulos, Int. J. Hydr. Ener. 44 (2019) 22816-22830, https://doi.org/10.1016/j.ijhydene.2019.07.040.

[29] J. Niu, Y. Wang, Y. Qi, A.H. Dam, H. Wang, Y.A. Zhu, A. Holmen, J. Ran, D. Chen, Fuel 266 (2020), 117143, https://doi.org/10.1016/j.fuel.2020.117143.

[30] S.A. Solov'ev, Y.V. Gubareni, Y.P. Kurilets, S.N. Orlik, Theor. Exp. Chem. 48 (2012) 199-205, https://doi.org/10.1007/s11237-012-9262-x.

[31] A.J. Majewski, J. Wood, Int. J. Hydr. Ener. 39 (2014) 12578-12585, https://doi. org/10.1016/j.ijhydene.2014.06.071.

[32] D.M. Walker, S.L. Pettit, J.T. Wolan, J.N. Kuhn, Appl. Catal. A Gen. 445-446 (2012) 61-68, https://doi.org/10.1016/j.apcata.2012.08.015.

[33] R.B. Duarte, F. Krumeich, J.A. van Bokhoven, ACS Catal. 4 (5) (2014) 1279-1286, https://doi.org/10.1021/cs400979q.

[34] Y. Tang, Y. Wei, Z. Wang, S. Zhang, Y. Li, L. Nguyen, L. Yixiao, Y. Zhou, W. Shen, F. F. Tao, P. Hu, J. Am. Chem. Soc. 141 (2019) 7283-7293, https://doi.org/10.1021/ jacs.8b10910.

[35] X. Zhao, H.T. Ngo, D.M. Walker, D. Weber, D. Maiti, U. Cimenler, A.D. Petrov, B. Joseph, J.N. Kuhn, Chem. Eng. Commun. 205 (2018) 1129-1142, https://doi. org/10.1080/00986445.2018.1434162.

[36] X. Zhao, D.M. Walker, D. Maiti, A.D. Petrov, M. Kastelic, B. Joseph, J.N. Kuhn, Ind. Eng. Chem. Res. 57 (2018) 845-855, https://doi.org/10.1021/acs.iecr.7b03669.

[37] H.P. Ren, Y.H. Song, Z.T. Liu, Z.W. Liu, ACS Symp. Series 1194 (2015) 155-169, https://doi.org/10.1021/bk-2015-1194.ch007.

[38] L.A. Schulz, L.C.S. Kahle, K.H. Delgado, S.A. Schunk, A. Jentys, O. Deutschmann, J. A. Lercher, Appl. Catal. A Gen. 504 (2015) 599-607, https://doi.org/10.1016/j. apcata.2015.03.002.

[39] L.C.S. Kahle, T. Roussière, L. Maier, K.H. Delgado, G. Wasserschaff, S.A. Schunk, O. Deutschmann, Ind. Eng. Chem. Res. 52 (2013) 11920-11930, https://doi.org/ 10.1021/ie401048w.

[40] L. Pino, A. Vita, F. Cipitì, M. Laganà, V. Recupero, Appl. Catal. B: Env. 104 (2011) 64-73, https://doi.org/10.1016/j.apcatb.2011.02.027.

[41] M. Lo Faro, A. Vita, L. Pino, A.S. Aricò, Fuel Proc. Technol. 115 (2013) 238-245, https://doi.org/10.1016/j.fuproc.2013.06.008.

[42] D. Sun, X. Li, S. Ji, L. Cao, J. Nat. Gas Chem. 19 (2010) 369-374, https://doi.org/ 10.1016/S1003-9953(09)60096-7.

[43] A. Vita, L. Pino, F. Cipitì, M. Laganà, V. Recupero, Fuel Proc. Technol. 127 (2014) 47-58, https://doi.org/10.1016/j.fuproc.2014.06.014.

[44] R.K. Singha, A. Shukla, A. Yadav, S. Adak, Z. Iqbal, N. Siddiqui, R. Bal, Acs Appl. Energy Mater. 178 (2016) 110-125, https://doi.org/10.1016/j. apenergy.2016.06.043.

[45] S.A. Solov'ev, Y.V. Gubareni, Y.P. Kurilets, S.N. Orlik, Theor. Exp. Chem. 48 (2012) 199-205, https://doi.org/10.1007/s11237-012-9262-x.

[46] L. Pino, A. Vita, M. Laganà, V. Recupero, Appl. Catal. B Env. 148-149 (2014) 91-105, https://doi.org/10.1016/j.apcatb.2013.10.043.

[47] C.E. Kozonoe, R.M.B. Alves, M. Schmal, Fuel 281 (2020), 118749, https://doi.org/ 10.1016/j.fuel.2020.118749.

[48] H.T. Jiang, H.Q. Li, Y. Zhang, J. Fuel Chem. Technol. 35 (2007) 72-78, https://doi. org/10.1016/S1872-5813(07)60012-7.

[49] R.K. Singha, S. Das, M. Pandey, S. Kumar, R. Bal, A. Bordoloi, Catal. Sci. Technol. 6 (2016) 7122-7136, https://doi.org/10.1039/C5CY01323B.

[50] M.D. Argyle, C.H. Bartholomew, Catalysts 5 (2015) 145-269, https://doi.org/ 10.3390/catal5010145.

[51] R. Kumar, K. Kumar, K.K. Pant, N.V. Choudary, Int. J. Hydr. Ener. 45 (2019) 1911-1929, https://doi.org/10.1016/j.ijhydene.2019.11.111.

[52] R. Kumar, K. Kumar, N.V. Choudary, K.K. Pant, Fuel Proc. Technol. 186 (2019) 40-52, https://doi.org/10.1016/j.fuproc.2018.12.018.

[53] N. Kumar, Z. Wang, S. Kanitkar, Appl. Petrochem. Res. 6 (2016) 201-207.

[54] A.V.P. Lino, Y.N.C. Calderon, V.R. Mastelaro, E.M. Assaf, J.M. Assaf, Appl. Surf. Sci. 481 (2019) 747-760, https://doi.org/10.1016/j.apsusc.2019.03.140.

[55] M. Tang, K. Liu, D.M. Roddick, M. Fan, J. Catal. 368 (2018) 38-52, https://doi org/10.1016/j.jcat.2018.09.022.

[56] S. Chen, L. Zeng, H. Tian, X. Li, J. Gong, ACS Catal. 7 (2017) 3548-3559, https:// doi.org/10.1021/acscatal.7b00436.

[57] S. Subramanian, Y. Song, D. Kim, C.T. Yavuz, ACS Ener. Lett. 5 (2020) 1689-1700, https://doi.org/10.1021/acsenergylett.0c00406.

[58] T.J. Siang, A.A. Jalil, M.Y.S. Hamid, A.A. Abdulrasheed, T.A.T. Abdullah, D.V. N. Vo, Fuel 278 (2020), 118360, https://doi.org/10.1016/j.fuel.2020.118360.

[59] T.J. Siang, A.A. Jalil, A. Abdulrahman, H.U. Hambali, Env. Chem. Lett. (2021), https://doi.org/10.1007/s10311-021-01192-0. 
[60] X. Shen, Y. Sun, Y. Wu, J. Wang, E. Jiang, X. Xu, J. Su, Z. Jia, Fuel 268 (2020) 117381, https://doi.org/10.1016/j.fuel.2020.117381.

[61] N. Rahmat, Z. Yaakob, N.S.M. Hassan, J. Ener. Institut. 96 (2021) 61-74, https:// doi.org/10.1016/j.joei.2021.02.001

[62] A.A. Abdulrasheed, A.A. Jalil, M.Y.S. Hamid, T.J. Siang, N.A.A. Fatah, S.M. Izan, N. S. Hassan, Int. J. Hydr. Ener. 45 (2020) 18549-18561, https://doi.org/10.1016/j ijhydene.2019.04.126.

[63] H.U. Hambali, A.A. Jalil, A.A. Abdulrasheed, T.J. Siang, T.A. Abdullah, A. Ahmad, D.V.N. Vo, Int. J. Ener. Res. 44 (2020) 5696-5712, https://doi.org/10.1002/ er.5327.

[64] A.V.P. Lino, C.B. Rodella, E.M. Assaf, J.M. Assaf, Int. J. Hydr. Ener. 45 (2020) 8418-8432, https://doi.org/10.1016/j.ijhydene.2020.01.002.

[65] J.M. García-Vargas, J.L. Valverde, F. Dorado, P. Sánchez, J. Mol. Catal. A Chem. 395 (2014) 108-116, https://doi.org/10.1016/j.molcata.2014.08.019.

[66] Y. Zhang, Y.F. Yao, Y.Y. Qiao, G.C. Wang, Phys. Chem. Chem. Phys. 23 (2021) 617-627, https://doi.org/10.1039/D0CP04732E.

[67] M. Akri, S. Zhao, X. Li, K. Zang, A.F. Lee, M.A. Isaacs, W. Xi, Y. Gangarajula, J. Luo, Y. Ren, Y.T. Cui, Nat. Comm. 10 (2019) 1-10, https://doi.org/10.1038/s41467019-12843-w.

[68] J. Du, J. Gao, F. Gu, J. Zhuang, B. Lu, L. Jia, G. Xu, Q. Liu, F. Su, Int. J. Hydr. Ener. 43 (2018) 20661-20670.

[69] C.J. Pan, M.C. Tsai, W.N. Su, J. Rick, N.G. Akalework, A.K. Agegnehu, S.Y. Cheng, B.J. Hwang, J. Taiwan Institut. Chem. Eng. 74 (2021) 154-186, https://doi.org/ 10.1016/j.jtice.2017.02.012.

[70] S.H. Lee, W. Cho, W.S. Ju, B.H. Cho, Y.C. Lee, Y.S. Baek, Catal. Today 87 (2003) 133-137, https://doi.org/10.1016/j.cattod.2003.10.005.

[71] H. Zou, S. Chen, J. Huang, Z. Zhao, Int. J. Hydr. Ener. 41 (2016) 16842-16850, https://doi.org/10.1016/j.ijhydene.2016.07.108.
[72] H. Jiang, H. Li, H. Xu, Y. Zhang, Fuel Proc. Technol. 88 (2007) 988-995, https:// doi.org/10.1016/j.fuproc.2007.05.007.

[73] C. Mateos-Pedrero, S.R. González-Carrazán, M.A. Soria, P. Ruíz, Catal. Today 203 (2013) 158-162, https://doi.org/10.1016/j.cattod.2012.02.039.

[74] A.V.P. Lino, E.M. Assaf, J.M. Assaf, J. $\mathrm{CO}_{2}$ Utiliz. 33 (2019) 273-283, https://doi. org/10.1016/j.jcou.2019.06.016.

[75] B. Rego de Vasconcelos, D. Pham Minh, E. Martins, A. Germeau, P. Sharrock, A. Nzihou, Int. J. Hydr. Ener. 45 (2020) 18502-18518, https://doi.org/10.1016/j. ijhydene.2019.08.068.

[76] H. Jiang, H. Li, H. Fan, Appl. Mech. Mater. 252 (2013) 255-258, https://doi.org/ 10.4028/www.scientific.net/AMM.252.255.

[77] S. Kim, B.S. Crandall, M.J. Lance, N. Cordonnier, J. Lauterbach, E. Sasmaz, Appl. Catal. B: Env. 259 (2019), 118037, https://doi.org/10.1016/j. apcatb.2019.118037.

[78] R. Kumar, K.K. Pant, Appl. Surf. Sci. 515 (2020), 146010, https://doi.org/ 10.1016/j.apsusc 2020.146010.

[79] G. Nahar, D. Mote, V. Dupont, Renew. Sustain. Ener. Rev. 76 (2017) 1032-1052, https://doi.org/10.1016/j.rser.2017.02.031.

[80] M.R. Kantserova, S.M. Orlyk, O.D. Vasylyev, Theor. Exp. Chem. 53 (2018) 387-394, https://doi.org/10.1007/s11237-018-9536-z.

[81] W. Yin, N. Guilhaume, Y. Schuurman, Chem. Eng. J. 398 (2020), 125534, https:// doi.org/10.1016/j.cej.2020.125534.

[82] S.A. Chattanathan, S. Adhikari, M. McVey, O. Fasina, Int. J. Hydr. Ener. 39 (2014) 19905-19911, https://doi.org/10.1016/j.ijhydene.2014.09.162.

[83] U. Izquierdo, I. García-García, A.M. Gutierrez, J.R. Arraibi, V.L. Barrio, J. F. Cambra, P.L. Arias, Catalysts 8 (2018) 12, https://doi.org/10.3390/ catal8010012. 